\title{
OsPhyB-Mediating Novel Regulatory Pathway for Drought Tolerance in Rice Root Identified by a Global RNA-Seq Transcriptome Analysis of Rice Genes in Response to Water Deficiencies
}

\author{
Yo-Han Yoo, Anil K. Nalini Chandran, Jong-Chan Park, Yun-Shil Gho, Sang-Won Lee, \\ Gynheung An and Ki-Hong Jung *
}

Graduate School of Biotechnology \& Crop Biotech Institute, Kyung Hee University, Yongin, South Korea

OPEN ACCESS

Edited by:

Ju-Kon Kim,

Seoul National University, South Korea

Reviewed by:

Nobuhiro Suzuki,

Sophia University, Japan

Men-Chi Chang,

National Taiwan University, Taiwan

*Correspondence:

Ki-Hong Jung

khjung2010@khu.ac.kr

Specialty section:

This article was submitted to

Plant Abiotic Stress,

a section of the journal

Frontiers in Plant Science

Received: 03 February 2017

Accepted: 30 March 2017

Published: 26 April 2017

Citation:

Yoo Y-H, Nalini Chandran AK,

Park J-C, Gho Y-S, Lee S-W, An G and Jung K-H (2017)

OsPhyB-Mediating Novel Regulatory

Pathway for Drought Tolerance in Rice Root Identified by a Global RNA-Seq

Transcriptome Analysis of Rice Genes

in Response to Water Deficiencies.

Front. Plant Sci. 8:580.

doi: $10.3389 / \mathrm{fp} / \mathrm{s} .2017 .00580$
Water deficiencies are one of the most serious challenges to crop productivity. To improve our understanding of soil moisture stress, we performed RNA-Seq analysis using roots from 4-week-old rice seedlings grown in soil that had been subjected to drought conditions for 2-3 d. In all, 1,098 genes were up-regulated in response to soil moisture stress for $3 \mathrm{~d}$, which causes severe damage in root development after recovery, unlikely that of $2 \mathrm{~d}$. Comparison with previous transcriptome data produced in drought condition indicated that more than $68 \%$ of our candidate genes were not previously identified, emphasizing the novelty of our transcriptome analysis for drought response in soil condition. We then validated the expression patterns of two candidate genes using a promoter-GUS reporter system in planta and monitored the stress response with novel molecular markers. An integrating omics tool, MapMan analysis, indicated that RING box E3 ligases in the ubiquitin-proteasome pathways are significantly stimulated by induced drought. We also analyzed the functions of 66 candidate genes that have been functionally investigated previously, suggesting the primary roles of our candidate genes in resistance or tolerance relating traits including drought tolerance (29 genes) through literature searches besides diverse regulatory roles of our candidate genes for morphological traits (15 genes) or physiological traits (22 genes). Of these, we used a T-DNA insertional mutant of rice phytochrome $B$ (OsPhyB) that negatively regulates a plant's degree of tolerance to water deficiencies through the control of total leaf area and stomatal density based on previous finding. Unlike previous result, we found that OsPhyB represses the activity of ascorbate peroxidase and catalase mediating reactive oxygen species (ROS) processing machinery required for drought tolerance of roots in soil condition, suggesting the potential significance of remaining uncharacterized candidate genes for manipulating drought tolerance in rice.

Keywords: phyb mutant, rice (Oryza sativa), RNA-seq, root, water deficiency 


\section{INTRODUCTION}

Water deficiencies at critical growth stages can seriously restrict crop productivity. One of the greatest challenges in providing adequate soil moisture is the erratic patterns and reduced amounts of rainfall due to climate change. Severe droughts now occur almost every year in rain-fed rice-growing regions of the world, drastically affecting yields from more than 20 million ha in South and Southeast Asia and nearly $80 \%$ of the area planted to rice in Africa (Pandey et al., 2007). Drought conditions can influence productivity to varying degrees depending upon the time of onset, duration, and intensity. For example, when plants are stressed during their reproductive stage, average yield losses can be more than 50\% (Boyer, 1982; Venuprasad et al., 2007).

Especially, functional identification of novel candidate genes will be valuable for future applications using gene editing or overexpression analyses. In rice, $<3 \%$ of nontransposable element genes $(1,022)$ in rice have been functionally characterized (Chandran et al., 2016). Information on the functionally characterized genes in rice is well-summarized in the Overview of functionally characterized Genes in Rice Online database (OGRO) on the Q-TARO website (http://qtaro.abr.affrc.go.jp/ogro). Regarding drought stress response, functions of 97 genes were introduced (Yamamoto et al., 2012). Stomatal conductance is one of the major mechanisms for conferring the drought tolerance in vegetative organs and functions of at least eight genes are related to this mechanism. Phytochrome B (PhyB) is negatively involved in drought tolerance through the regulation of stomatal density (Liu J. et al., 2012). Calmodulin-like (CML) genes are known to regulate plant responses to abiotic stresses including drought. Transgenic plants over-expressing OsCML4 gene confer drought tolerance through ROS-scavenging process (Yin et al., 2015). In addition, abscisic acid (ABA) is a representative hormone closely associated with abiotic stresses including drought and at least eight genes are involved in $\mathrm{ABA}$ relating drought stress responses. Of them, $A B A$ responsive AP2-like gene 1 ( $A R A G 1$ ) is related to drought tolerance during seedling stage and ABA sensitivity during germination (Zhao et al., 2010). In addition, the correlation between stomatal response and $\mathrm{ABA}$ is very important for studying the mechanism on the drought tolerance (Daszkowska-Golec and Szarejko, 2013). Root architecture is closely related to how vulnerable a plant will be to drought stress. Functions of a few genes have been reported in the association with both drought stress and root development. Of them, DEEPER ROOTING 1 (DRO1) regulates cell elongation at the root tip and increased expression of DRO1 changes the angle of growth so that roots develop in a more downward direction (Uga et al., 2013). Furthermore, root-specific overexpression of OsNAC10 enlarges the roots, enhancing drought tolerance in field-grown transgenic plants and significantly increasing their grain yields under deficit conditions (Jeong et al., 2010). Thus, root-driven drought tolerance is more effective for current and future applications but our knowledge on this process is still limited.

Genome-wide transcriptome analysis is very general and powerful tool to quickly improve global understanding on this stress response. Until now, 18 series of whole genome transcriptome analyses have been performed using microarray or RNA-seq technologies. Of these, only one experiment analyzed transcriptomes in roots exposed to drought in two growth stages, tillering and panicle elongation stages, due to the difficulty of the root sampling under drought stress (Wang et al., 2011). However, physiological features of the root samples which is required for quality check of the samples used for the transcriptome analyses were not well-evaluated, limiting further applications. In addition, the detailed data analysis including in planta validation of the gene expression patterns, functional validation using mutants, functional classification, protein-protein interaction network, and integrating omics analysis were not provided (Chandran and Jung, 2014).

To monitor changes in gene expression when rice roots are exposed to water-deficiency stress under soil condition, we conducted RNA-Seq analysis, comparing roots samples under 2-3 d of induced stress vs. those from the well-watered (unstressed) control. The metabolic/regulatory pathways and biological processes for coping with this challenge were explored via Gene Ontology (GO) enrichment and MapMan analyses. We also examined the activity promoters of genes induced by drought conditions, using the GUS reporter system and developed a functional gene network to quickly understand the regulatory pathway. Functional significance for drought tolerance in root of our candidate genes is evaluated through the analysis of osphyb mutant carrying a T-DNA insertion in the coding sequence region, suggesting novel regulatory mechanism for the drought tolerance in rice.

\section{MATERIALS AND METHODS}

\section{Plant Materials and Stress Treatments}

Plants of japonica rice (Oryza sativa) cv. Chilbo were grown in plastic pots for 4 weeks in an incubator [14-h light/10-h dark, $28^{\circ} \mathrm{C}$ (day) $/ 22^{\circ} \mathrm{C}$ (night), humidity $80 \%$; Younghwa Science, Daegu, Korea]. On average, $300 \mathrm{~g}$ of dried soil was used to grow 10 plants in each pot. The effects of drought stress were measured at various time points, including 1,2,3, and $4 \mathrm{~d}$ after irrigation was withheld and then at $7 \mathrm{~d}$ after they were re-watered. Our mock treatment comprised a group of rice plants that continued to receive normal irrigation throughout the experimental period. To observe the physiological features between phyb mutants and wild type segregants, we used samples collected before water deficiency treatment (WD), $3 \mathrm{~d}$ after $\mathrm{WD}$, and $7 \mathrm{~d}$ after rewatering. In three time points, we observed the root morphology of phyb mutants and wild type segregants.

\section{RNA-Seq Analysis}

We used the illumina platform to generate sequence reads ( $26 \mathrm{~GB})$ that comprised six transcriptome samples from the 2-d to 3-d drought-stressed plants plus the untreated control. In all, 100-bp paired-end reads were assessed with a FastQC toolkit (Andrews, 2010). Any adapter contaminations and low-quality reads (-phred33 and -q 20) were removed using both Cutadapt (Martin, 2011) and its wrapper tool, Trimgalore (Krueger, 2012). The resultant high-quality reads 
were taken for our TopHat pipeline, as described (Trapnell et al., 2013). On average, $94 \%$ of the filtered reads were mapped to the International Rice Genome Sequencing Project (IRGSP) 1.0 reference genome (Kawahara et al., 2013) and the gene features were estimated based on the gff3 annotation file provided in the Rice Genome Annotation Project (RGAP) database (http://rice.plantbiology.msu.edu/; Ouyang et al., 2007). Differentially expressed genes (DEGs) were evaluated by using Cuffdiff to compare between treatment conditions. Genes with $p<0.05$ and $\log _{2}$ fold-changes $>1$ (i.e., fold-change $>2$ ) were considered differentially expressed. Further screening among the initial DEGs was done based on fragments per kilo-base per million fragments mapped (FPKM) values (Trapnell et al., 2013). The GEO accession number is GSE92989.

\section{GUS Assays}

To examine GUS expression patterns, we germinated seeds from two promoter trap lines in a Murashige and Skoog (MS) medium for $7 \mathrm{~d}$. The resultant plantlets were then air-dried for $0.0,0.5$, 1.0, 2.0, or $4.0 \mathrm{~h}$. Afterward, whole seedlings from all treatment groups were soaked for $30 \mathrm{~min}$ in a GUS-staining solution before their roots were photographed with a camera (Canon EOS 550D; Canon, Tokyo, Japan).

\section{Analysis of Cis-Acting Elements}

To identify any consensus cis-acting regulatory elements (CREs) in the promoters of our drought-inducible genes, we extracted 2-kb upstream sequences of ATG for LOC_Os04g52290 and LOC_Os07g02710 that had been validated through GUS assays in the current study plus those of LOC_Os09g35790 and LOC_Os02g04650, which have previously been reported as drought-inducible promoters based on the promoterGUS system (Rerksiri et al., 2013; Jeong and Jung, 2015) from PLANTPAN (http://plantpan2.itps.ncku.edu.tw/; Chang et al., 2008). MEME searches were then performed with those sequences in the FASTA format via the Web server hosted by the National Biomedical Computation Resource (http://meme-suite.org/). We looked for up to four CREs with 10 maximum motif widths. Using the Motif Alignment and Search Tool (MAST) tool, we then searched DNA sequences for matches to the putative TF-binding site motifs found by the motif comparison tool (TOMTOM) within a set of promoter sequences (Bailey et al., 2006).

\section{Analysis of Gene Ontology Enrichment}

We employed the GO enrichment tool (Cao et al., 2012) to determine the biological roles of selected genes listed in the Rice Oligonucleotide Array Database (Jung et al., 2008b). This included any genes that were up-regulated during the $3 \mathrm{~d}$ of WD treatment. A fold enrichment value higher than standard (1) meant the selected GO term was over-represented. Terms with $>2$-fold enrichment values were also considered.

\section{MapMan Analysis}

The rice MapMan classification systems covers 36 BINs, each of which can be extended in a hierarchical manner into subBINs (Usadel et al., 2005; Urbanczyk-Wochniak et al., 2006). Using diverse MapMan tools, a significant gene list selected from highthroughput data analysis can be integrated to diverse overviews. Here, we generated a dataset carrying locus IDs from RGAP in addition to average $\log _{2}$ fold-change data for WD vs. mock treatment (control) conditions. For describing any genes upregulated in response to $3 \mathrm{~d}$ of drought, we used four overviews: Metabolism, Regulation, Transcription, and Proteasome.

\section{Analysis of Rice Genes with Known Functions}

To evaluate the functional significance of our candidate genes, we compared our gene list with the Overview of functionally characterized Genes in Rice Online database (OGRO, http://qtaro.abr.affrc.go.jp/ogro), which summarize rice genes with known functions (Yamamoto et al., 2012).

\section{Analysis of a Predicted Protein-Protein Interaction Network}

Using the Rice Interactions Viewer tool (http://bar.utoronto.ca/ interactions/cgi-bin/rice_interactions_viewer.cgi; Chandran and Jung, 2014), we generated a hypothetical protein-protein interaction network involving transcription factors (TFs), kinases, transporters, and functionally characterized genes. The network was edited with the Cytoscape tool (3.2.0 version; Shannon et al., 2003).

\section{$\mathrm{H}_{2} \mathrm{O}_{2}$ Measurement and Antioxidant Enzyme Assay}

Four-week-old seedlings of phyb mutants and wild type (WT) segregants (control) were subjected to drought stress for $3 \mathrm{~d}$ (drought-stressed) and then grown for $7 \mathrm{~d}$ after they were rewatered (recovered). Recovered, drought-stressed and control root samples were collected, and immediately frozen in liquid nitrogen and stored at $-80^{\circ} \mathrm{C} . \mathrm{H}_{2} \mathrm{O}_{2}$ measurement, activity of ascorbate peroxidases (APX) and catalase (CAT) enzymes were performed as described previously (Garg et al., 2012). All experimental data were recorded as the means of three independent experiments.

\section{Quantitative Real-Time PCR (qRT-PCR) Analysis}

Our quantitative real-time PCR (qRT-PCR) analysis was conducted as follows. Roots were sampled from WT and phyb mutant plants at 4 weeks old and immediately frozen in liquid nitrogen. After total RNAs were isolated using RNAiso kits (Takara Bio, Shiga, Japan), first-strand cDNA was synthesized with MMLV Reverse Transcriptase (Promega, WI, USA) and the oligo(dT) 15 primer. Synthesized cDNAs were amplified using a SYBR Premix Ex Taq (TaKaRa) before qRT-PCR was performed on a Rotor-Gene Q instrument system (Qiagen, Hiden, Germany). For normalizing the amplified transcripts, we used a primer pair for rice ubiquitin 5 (OsUbi5/Os01g22490; Jain et al., 2006). All primers for these analyses are summarized in Table S1. 


\section{RESULTS}

\section{Physiological Responses of Rice Roots Exposed to a Water Deficiency}

Four-week-old rice seedlings grown in an incubator were exposed to a water deficit for $1,2,3$, or $4 \mathrm{~d}$ (Figures 1A-D). After then, we rewatered rice seedlings in all stressed conditions and had grown them for $7 \mathrm{~d}$. Most of the rice plants that were drought-treated for 2 days (2 WD) were not recovered but those treated for 3 days were mostly recovered (Figures $\mathbf{1 E}-\mathbf{H}$ ). To identify the DEGs in root samples, we compared between the WD treatment $(1-4 \mathrm{~d})$ and mock treatment (control) plants. The expression patterns were then examined for two genes that had been identified as molecular markers of the drought-stress response, i.e., OsDREB2b (LOC_Os05g27930) and OsbZIP23 (LOC_Os02g52780) (Xiang et al., 2008; Matsukura et al., 2010). As expected, stressed roots (from Days 3 to 4) showed increased expression of those genes (Figures 1I,J). After then, we observed the morphological features and measured the dry weight (Figures 2A-E). As a result, the dry weights of the root samples under WD were not changed, while that of untreated control is increasing. In addition, we identified that dry weight after recovery of root samples exposed to WD stress for $2 \mathrm{~d}$ increased, whereas that of root samples exposed to WD stress for $3 \mathrm{~d}$ decreased and finally the rice plants were mostly died due to the damage augmented by the stress (Figures 2F-J). This result indicates that WD stress for $3 \mathrm{~d}$ is a critical time point in our experimental condition to determine the survival under WD stress. Thus, it will be very important to know the mechanism how plant roots overcome unfavorable growth condition caused by long duration expose to WD stress.

\section{Genome-Wide Identification via RNA-Seq of Rice Genes Induced by a Water Deficiency}

Transcriptome analysis was conducted with RNA-Seq technology using roots from control (C) and WD plants ( 2 or $3 \mathrm{~d}$ of water stress). In the 2-d treatment, 716 genes were up-regulated and 787 genes were down-regulated when compared with the control (Figure 3A, Table S2). In the 3-d trial, 1,098 genes were up-regulated and 865 genes were down-regulated (Figure 3B, Table S3). In all, 585 up-regulated genes were common to both test periods (Figure S1). For closer examination, we focused on genes that were up-regulated after $3 \mathrm{~d}$ of drought treatment because we had determined that this length of time is riskier for rice plants, based on their survival rates. A heat-map was constructed with data for $\log _{2}$ fold-change values between WD and control roots, and $\log _{2}$ intensities in all replicates of 1,963 DEGs, including upregulation and downregulation (Figure 3B, Table S3).
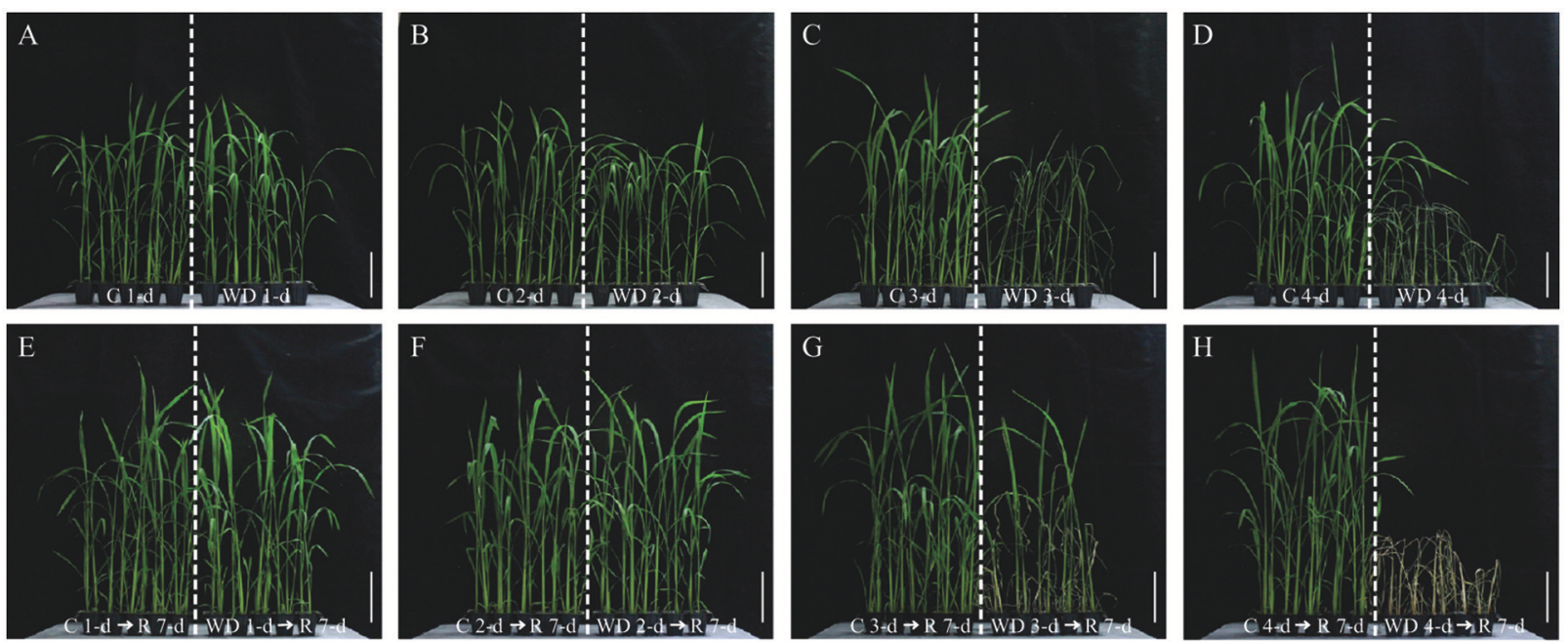

I

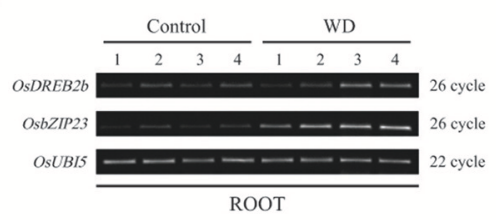

$\mathrm{J}$
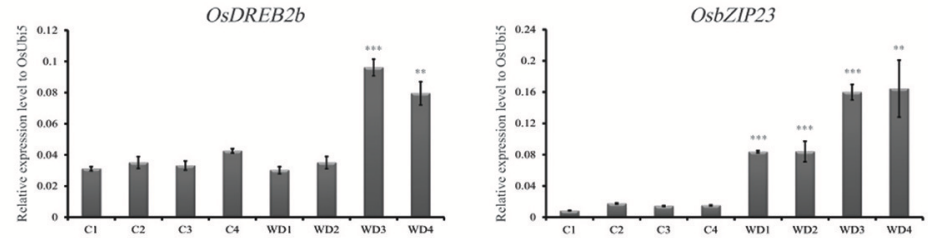

FIGURE 1 | Physiological responses under drought stress of rice seedlings grown in soil. Rice cultivar Chilbo grown in plastic pots for 4 weeks was exposed to water deficiency (WD) for 1 (A), 2 (B), 3 (C), or 4 (D) $d$ and then recovered for 7-d (E-H). Effects of WD were checked by monitoring expression patterns of drought-stress marker genes (I,J). Y-axis indicates expression level relative to OsUBI5/Os01g22490 (internal control); X-axis, samples used for qRT-PCR (J). C1, C2, C3, and C4, untreated control (roots from well-watered pots) corresponding to plants under $1 \mathrm{~d}$ of water deficiency (WD1d), 2d (WD2d), 3d (WD3d), and 4 d (WD4d). ${ }^{\star \star} P<0.01 ;{ }^{\star \star \star} P<0.001$. Scale bar $=10 \mathrm{~cm} . N=3$. 

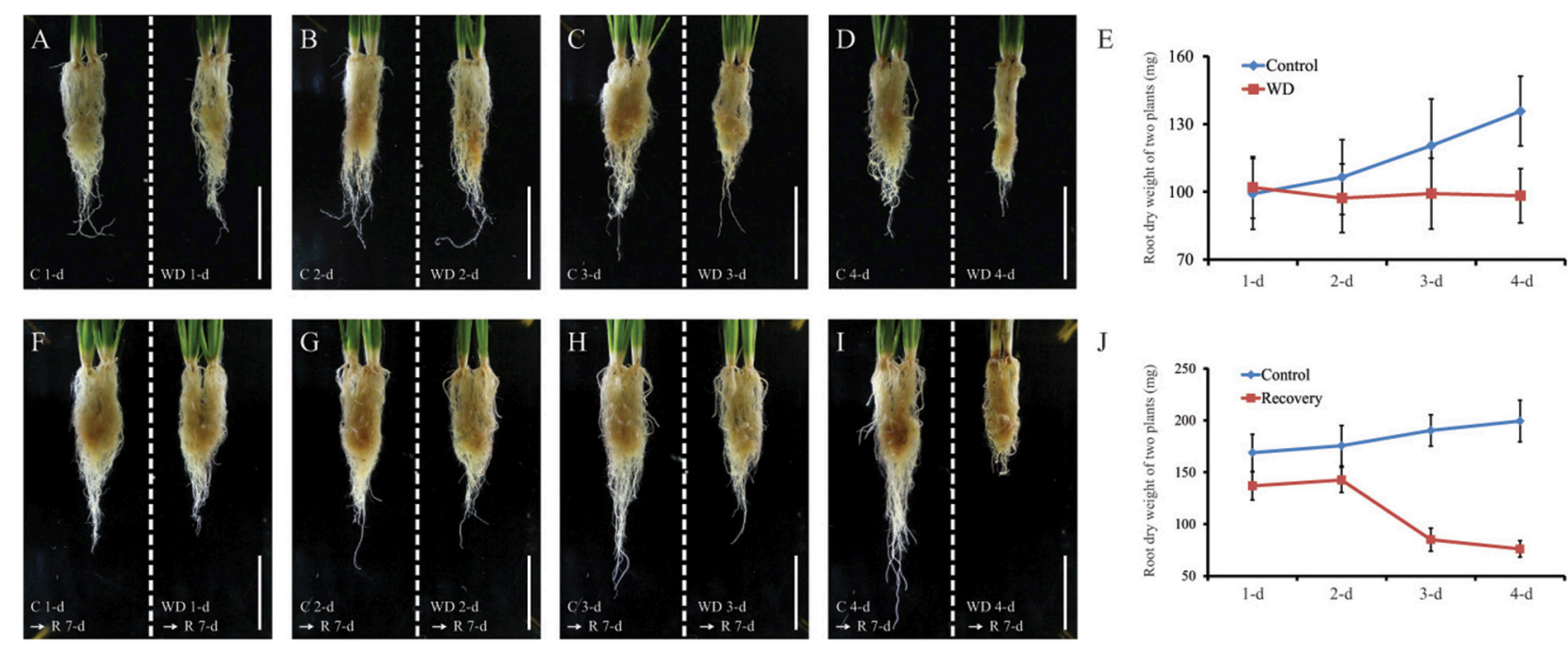

FIGURE 2 | Physiological responses under drought stress of rice roots grown in soil. The plants grown for 4 weeks was exposed WD for 1, 2, 3, or $4 \mathrm{~d}$ and the dry weight was measured in roots (A-E). After 7-d of recovery, dry weight was measured (F-J). C1, C2, C3, and C4, untreated control (roots from well-watered pots) corresponding to plants under $1 \mathrm{~d}$ of water deficiency (WD1d), $2 \mathrm{~d}$ (WD2d), 3d (WD3d), and $4 \mathrm{~d}$ (WD4d). Scale bar $=5 \mathrm{~cm}$. $N=3$ for (A-D, F-I); and $n=200$ for (E,J).

A

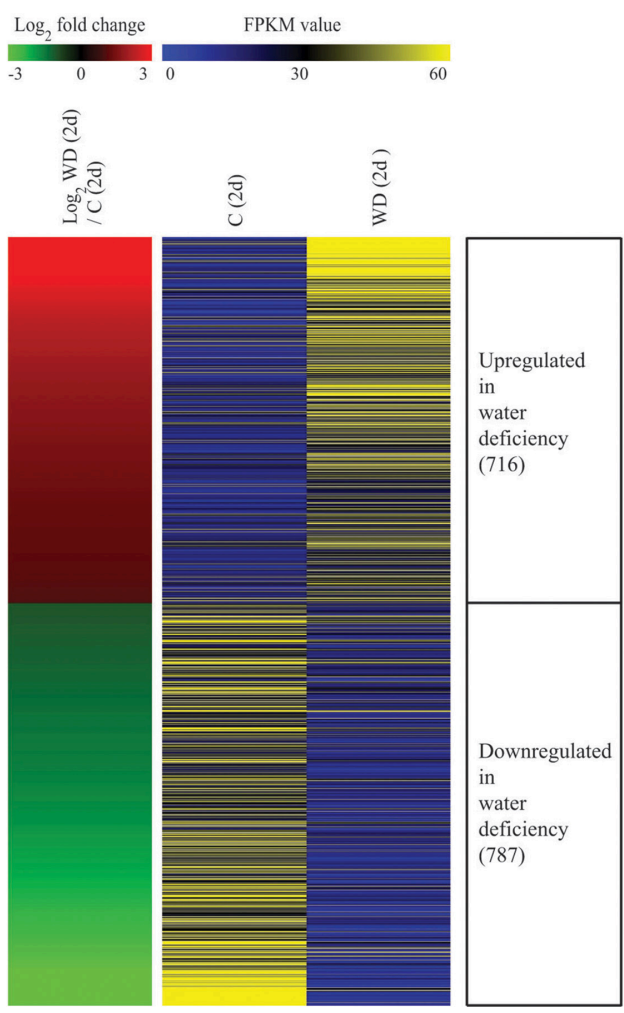

B
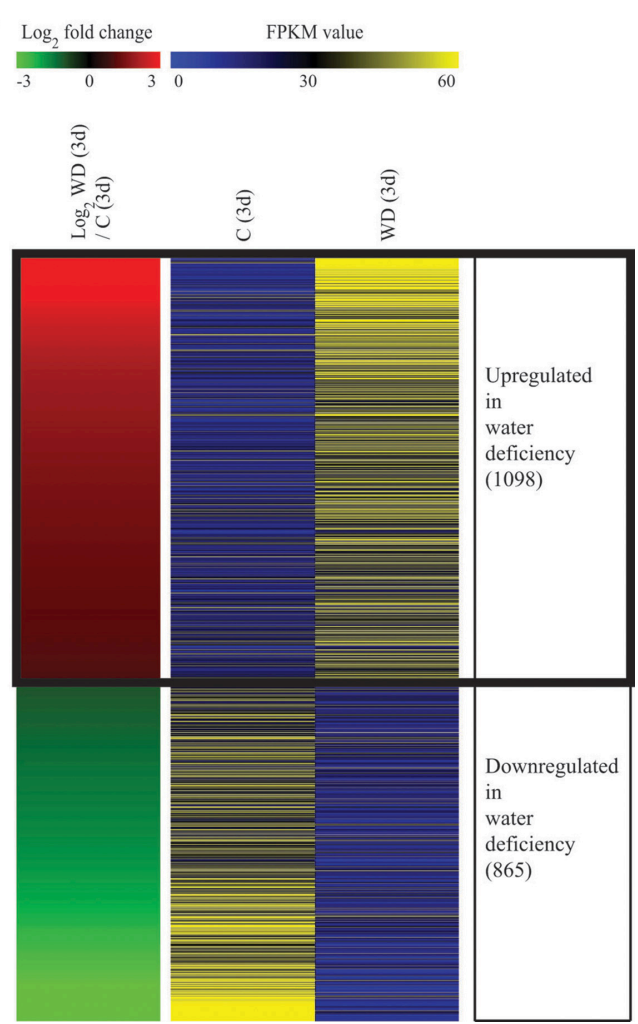

FIGURE 3 | Heatmap of differentially expressed genes under drought stress. Using RNA-Seq data processing under criteria of FPKM > 4, $p<0.05$, and ratio of $<-1.0$ for $1<\log _{2}$ roots exposed to water deficiency (WD) vs. mock-treated rice roots (Control, C), we identified 1,503 differentially expressed genes (DEGs) after 2 d of drought treatment (A) and 1,963 DEGs after $3 \mathrm{~d}$ of treatment (B). In left panel, red color indicates upregulation in WD/C comparison; green, downregulation in WD/C comparison. Right panel shows average normalized FPKM values from RNA-Seq experiments; blue indicates lowest expression level and yellow, highest level. Detailed data about RNA-Seq analysis are presented in Tables S3, S4. 


\section{Validation of Drought-Inducible Genes in Rice Roots Using GUS Reporter System and qRT-PCR}

Promoter traps employing the GUS reporter gene system have been used to identify promoters involved in regulating tissuespecific and stress-responsive expression patterns (Jung et al., 2005, 2006, 2015). Our RNA-Seq data analysis revealed 98 genes showing $>3$ ( $\log _{2}$ scale)-fold upregulation by stress when compared with the control (Table S3). We then searched the potential promoter trap lines of 38 genes and examined GUS expression patterns in 7-d-old seedlings. Among these, the promoter trap lines of two genes (PFG 3A-03417 for LOC_Os04g52290 and PFG 3A-13738 for LOC_Os07g02710) displayed GUS expression in the roots after plants were exposed to a water deficit for $0-4$ h (Figures 4A,C, Figure S2). We noted with interest that longer exposure to stress (i.e., 2-4 h) was associated with stronger GUS expression. This drought-related expression was verified by qRT-PCR (Figures 4B,D). However,

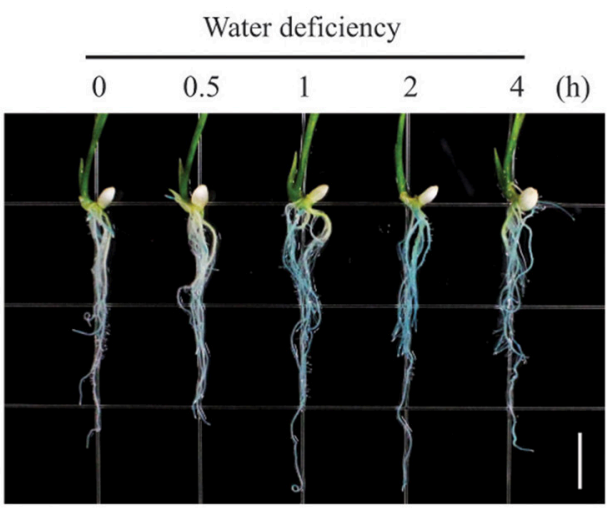

B

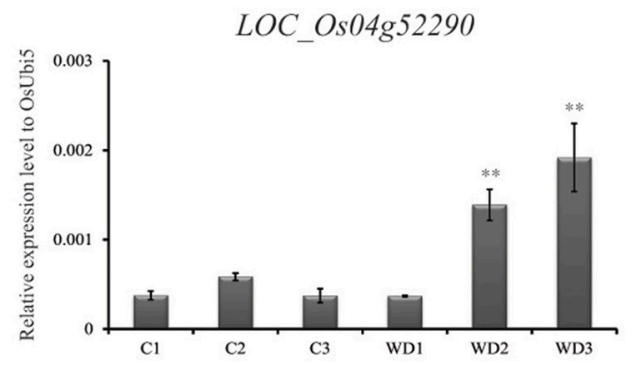

C

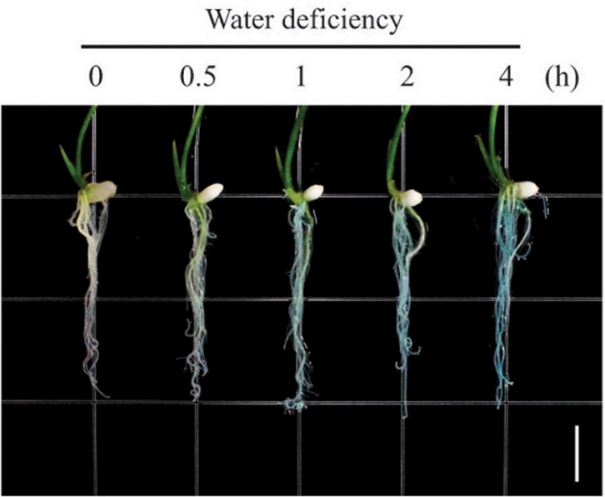

D

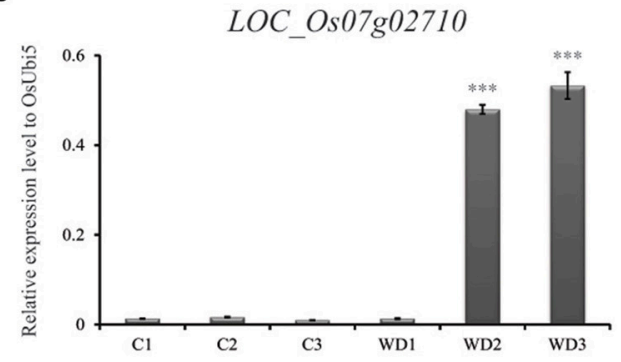

E

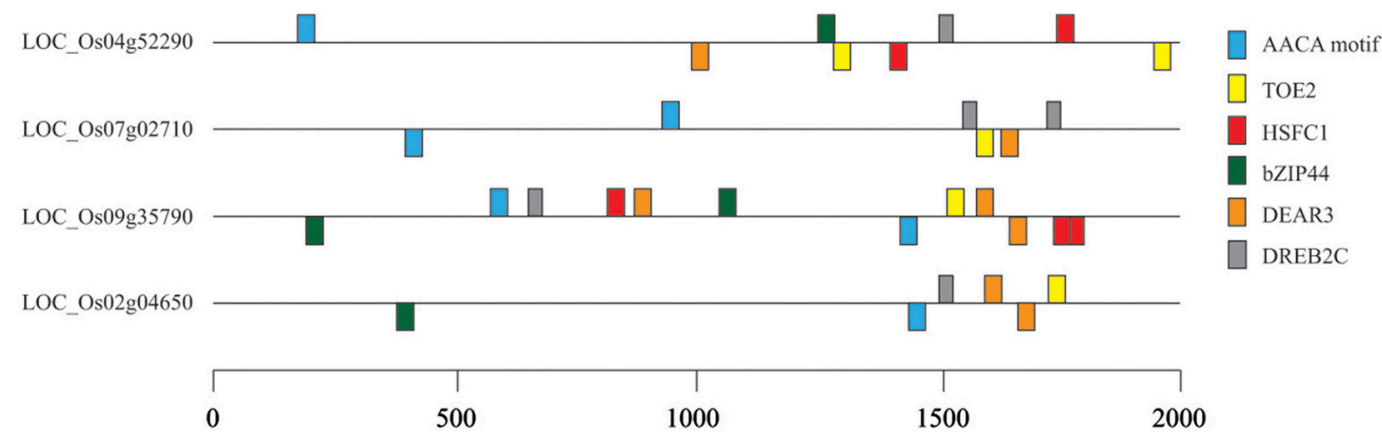

FIGURE 4 | Confirmation of water deficiency-inducible gene expression patterns in rice roots using GUS reporter system and qRT-PCR. To identify in planta expression of selected candidates, we germinated seeds for 2 promoter trap lines (LOC_Os04g52290/3A-03417 and LOC_Os07g02710/3A-13738) in Murashige and Skoog (MS) medium for $7 \mathrm{~d}$ and air-dried plantlets for 0.0, 0.5, 1.0, 2.0, or $4.0 \mathrm{~h}$. Whole seedlings were then incubated for $1 \mathrm{~h}$ in GUS-staining solution, respectively (A,C). Expression of two genes was significantly up-regulated by WD, based on GRT-PCR (B,D). C1, C2, and C3, untreated control (roots from well-watered pots) corresponding to plants under $1 \mathrm{~d}$ of water deficiency (WD1), $2 \mathrm{~d}$ of stress (WD2), and $3 \mathrm{~d}$ of stress (WD3). ${ }^{* *} P<0.01$; ${ }^{* \star *} P<0.001$. Identification of 6 conserved CREs of water deficiency-inducible genes (E). MEME tool was used to find consensus elements in promoter regions of four genes showing GUS induction under water deficiency. Numerals at bottom indicate positions of nucleotides starting from ATG. Detailed information is presented in Table 1. 
the other lines did not show GUS activity, indicating that they were not real promoter trap lines. The efficiency (7.2\%) showing GUS activity in the promoter trap candidate lines is a little higher than previous reports (Jeon et al., 2000; Jeong et al., 2002). Our findings demonstrated that the promoter trap system, when combined with qualified genome-wide transcriptome data, is a very effective way to identify the activity of an endogenous promoter. This also enables researchers to develop novel promoters.

\section{Analysis of Cis-Acting Elements in Two Drought-Inducible Genes Confirmed by the GUS Reporter System}

To identify the CREs involved in the response to a water deficit, we used two promoters from this study plus two that have shown both WD-inducible expression patterns using GUS reporter systems (from previous studies) as well as significant upregulation in our RNA-Seq data (Rerksiri et al., 2013; Jeong and Jung, 2015). In total, the promoters of four genes displaying significant upregulation in stressed roots were analyzed using the MEME tool (Bailey et al., 2006). From these, we found an AACA motif, a target of early activation tagged (EAT) 2 (TOE2), dehydration response element binding factor 3 (DREB3), and dehydration-responsive element-binding 2C factor (DREB2C) elements (Figure 4E, Table 1). Because they were common to all of our selected promoters, we propose that they will be crucial in future efforts to manipulate responses against water deficiencies in rice roots.

\section{Analysis of Gene Ontology Enrichment Reveals Biological Processes Associated with Water-Deficiency Responses in Rice Roots}

To determine the functions of 1,098 genes up-regulated by drought in rice roots, we studied the GO terms of those genes within the "biological process" category. In all, 19 terms

TABLE 1 | Summary of cis-acting regulatory elements identified in rice in response to water deficiency.

\begin{tabular}{|c|c|c|c|}
\hline CREs $^{a}$ & Sequence & Function & References \\
\hline $\begin{array}{l}\text { AACA } \\
\text { motif }\end{array}$ & AACAAAA & $\begin{array}{l}\text { Found in promoter region of } \\
\text { cereal storage proteins }\end{array}$ & Boronat et al., 1986 \\
\hline TOE2 & стсстсстсс & TOE2 (AP2 domain) & $\begin{array}{l}\text { Franco-Zorrilla et al., } \\
2014\end{array}$ \\
\hline HSFC1 & AGCTTCCAG & $\begin{array}{l}\text { HSFC1 (HSF-type } \\
\text { DNA-binding, } \\
\text { Interferon-induced } 35 \mathrm{kDa} \\
\text { protein (IFP 35) N-terminus) }\end{array}$ & $\begin{array}{l}\text { Franco-Zorrilla et al., } \\
2014\end{array}$ \\
\hline bZIP44 & GGCCACGTC & $\begin{array}{l}\text { bZIP transcription factor } \\
\text { binding domain }\end{array}$ & Mathelier et al., 2014 \\
\hline DEAR3 & CCCCGCCCGC & DEAR3 (AP2 domain) & $\begin{array}{l}\text { Franco-Zorrilla et al., } \\
2014\end{array}$ \\
\hline DREB2C & CGGCCGGGCC & DREB2C (AP2 domain) & $\begin{array}{l}\text { Franco-Zorrilla et al., } \\
2014\end{array}$ \\
\hline
\end{tabular}

aIndicates cis-acting regulatory elements. were highly over-represented in our gene list, with $p<0.05$ and fold-enrichment values of $>2\left(\log _{2}\right)$-fold, as we have also previously reported (Jung et al., 2008b; Table S4).

Of these, "valyl-tRNA aminoacylation" (14.0-fold enrichment) was the most significantly enriched by drought stress. Metabolic profiling of Pisum sativum L. (Charlton et al., 2008) has shown that valine along with threonine, leucine, and isoleucine are important metabolites that are most highly accumulated in response to a water deficit. Moreover, the levels of branched chain amino acids, such as valine, leucine, and isoleucine are greatly increased under water stress in leaf tissues from cultivars of wheat (Triticum aestivum; Bowne et al., 2012). All of these results suggest that aminoacylation of valyl-tRNA might be activated during drought periods.

Genes for "phospholipid biosynthetic process" (11.5), "thiamin biosynthetic process" (7.7), "cysteine biosynthetic process from serine" (7.4), "glycogen biosynthetic process" (6.3), and "cellular amino acid biosynthetic process" (4.7) also have important roles in the abiotic-stress response (Figure 5). For example, Phospholipase C (PLC) plays a role in catalyzing hydrolysis and AtPLC1 gene is known to be induced by drought and salt stresses (Hirayama et al., 1995). Furthermore, thiamine (vitamin B1) is up-regulated under salinity or osmotic-stress conditions by abscisic acid (ABA) in Arabidopsis thaliana (Rapala-Kozik et al., 2012). Transgenic Arabidopsis plants over-expressing $T$. aestivum cysteine protease exhibit higher drought tolerance and greater cysteine protease activity under water-stress conditions than do WT plants (Zang et al., 2010). The effects of lipids on signaling, intracellular trafficking, and cytoskeletal organization also have important roles in responses to drought and salinity (Wang et al., 2007). We also identified other significant GO terms such as "catabolic process," "Transport," and "etc." that are significant in the drought response (Figure 5). Therefore, the biological processes identified here as being closely associated with WD might prove to be novel resources for improving our understanding about the molecular mechanism and components involved in conferring plant tolerance to moisture stress.

\section{MapMan Analysis of Water Deficiency-Related Genes in Rice Roots}

The MapMan program is very effective for visualizing diverse overviews associated with high-throughput transcriptome data (Jung and An, 2012). We uploaded fold-change data and Locus IDs for 1,098 upregulated genes (Table S3) to various overviews installed in that program.

To investigate the significant metabolic pathways involved in the response to water-deficiency stress, we analyzed the Metabolism overview associated with 1,098 genes (Figure 6). Amino acid metabolism (19 elements), lipids (16), secondary metabolism (14), cell walls (14), nucleotides (5), mitochondrial electron transport (5), photosystems (4), and the Calvin Cycle (3) were clearly related to this stress (Figure 6A, Tables S5, S6). These results implied that rice roots might trigger the above metabolic pathways to increase drought tolerance. Our Regulation overview of 1,098 genes demonstrated that 104 TFs, 


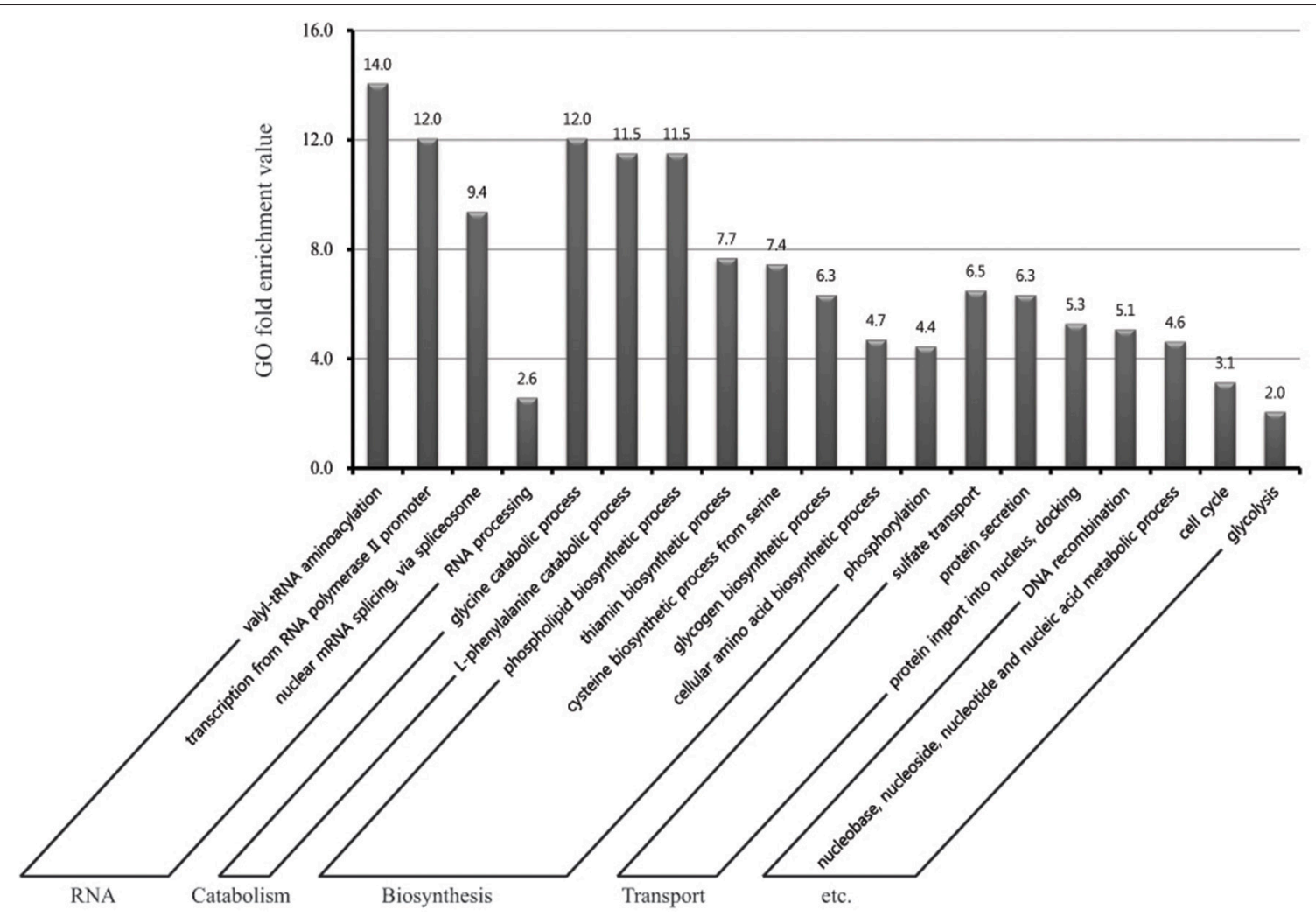

FIGURE 5 | Gene ontology (GO) enrichment analysis in "biological process" category for genes up-regulated in response to water deficiency. In all, 19 GO terms were over-represented under $>2$-fold enrichment value, with $p<0.05$. Details of GO assignments are presented in Table S5.

29 genes related to protein modification, and 50 genes associated with protein degradation were expressed in rice roots during periods of water stress (Figure 6B). Of these, TFs were the most abundant, meaning that they are largely involved in regulating the response and tolerance of rice to drought conditions. Therefore, those genes are considered potential candidates for further study.

Accordingly, we found nine myeloblastosis (MYB) oncogenes, six Apetala2/Ethylene Responsive Element Binding Proteins (AP2/EREBPs), five Basic Helix-Loop-Helix (bHLH) genes, four homeobox genes, four Chromatin Remodeling Factors, four SET-domains, three WRKY domains, two Cys2His2 (C2H2) zinc fingers, two $\mathrm{C} 3 \mathrm{H}$ zinc fingers, two MADS box genes, two members of the TEOSINTE BRANCHED1, CYCLOIDEA, AND PCF FAMILIES, and two basic leucine zipper (bZIP) TFs for water-deficiency stress (Figure 6C, Tables S5, S6). Dehydration-responsive element-binding protein (DREB) is part of a subfamily of the AP2/EREBP and plays a significant role in the abiotic-stress response by specifically binding to the dehydration-responsive element/C-repeat (DRE/CRT) cis-acting element (Mizoi et al., 2012). For example, OsDREB1C, $O s D R E B 1 F$, and OsDREB2A are constitutively expressed under drought conditions (Dubouzet et al., 2003; Wang et al., 2008), and overexpression of OsDREB1F, OsDREB1G, and OsDREB2A improves tolerance to moisture stress by transgenic rice plants (Chen et al., 2008; Wang et al., 2008; Cui et al., 2011).
Likewise, bZIP, MYB, and WRKY genes have been explored for their ability to improve drought tolerance in rice. OsbZIP16, OsbZIP23, OsbZIP46, OsbZIP71, and OsbZIP72 have critical functions in ABA signal transduction and they positively regulate drought tolerance (Xiang et al., 2008; Lu et al., 2009; Chen et al., 2012; Tang et al., 2012; Liu et al., 2014). Rice gene OsMYB4 has a positive role in conferring drought tolerance when expressed in transgenic plants of Malus domestica and Solanum lycopersicum (Vannini et al., 2007; Pasquali et al., 2008). As an R2R3-type MYB gene, OsMYB2 over-expressed in plants makes them more tolerant to salt, cold, and dehydration while overexpression of OsMYB48-1, another MYB-related TF, increases drought and salinity tolerance in rice (Yang et al., 2012; Xiong et al., 2014). Increased expression of OsWRKY11 under the control of HSP101 promoter also leads to enhanced drought tolerance ( $\mathrm{Wu}$ et al., 2009), as does overexpression of OsWRKY45 (Tao et al., 2011). In addition, various TFs, e.g., NAC, bHLH, Zinc fingers, and homeobox genes, are involved in the plant response to water deficits (Zhang et al., 2016).

We found that the responses of RING-finger E3 ligases (18 elements), Ubiquitin E3 F-Box (5), and ubiquitin protease (2) were clearly related to drought stress (Figure 6D, Tables S5, S6). For example, OsDIS1 is a C3HC4 RING finger E3 ligase, and the RNAi transgenic plants are tolerant to drought stress (Ning et al., 2011). The RING-finger containing E3 ligase O. sativa 
A

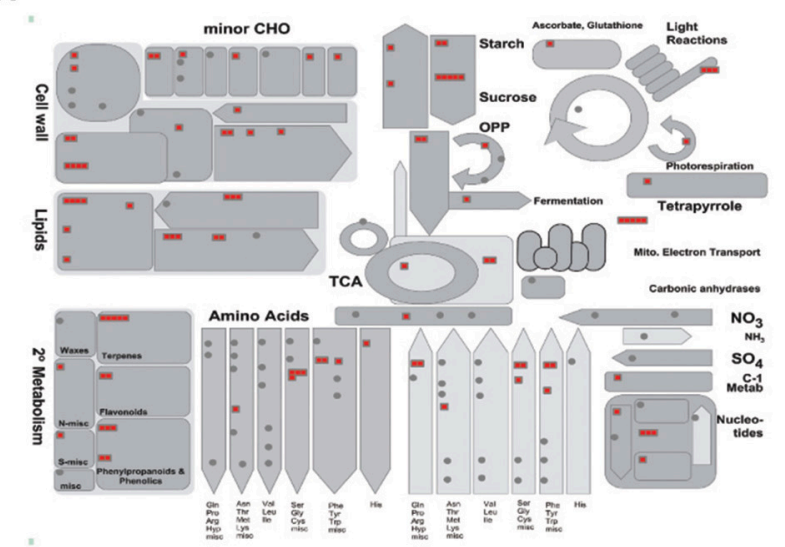

C

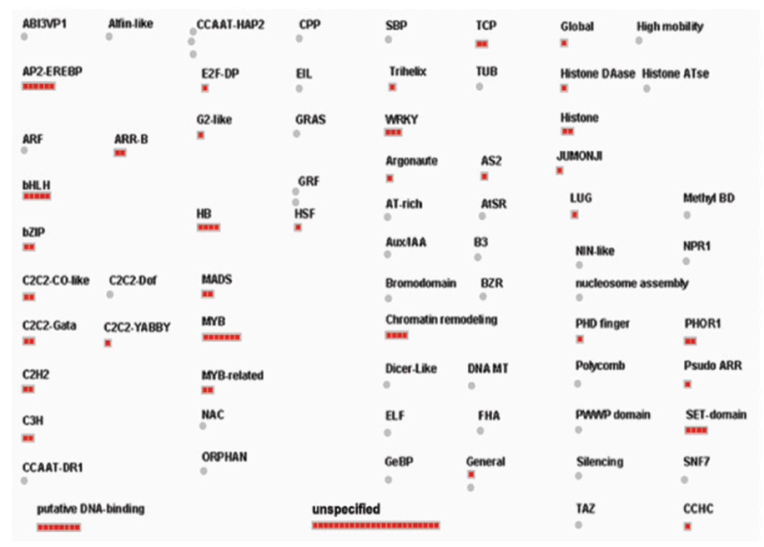

B

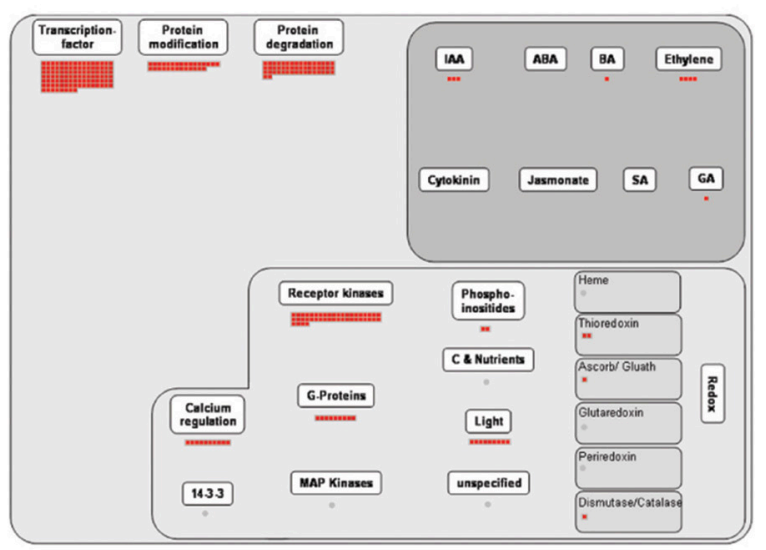

D

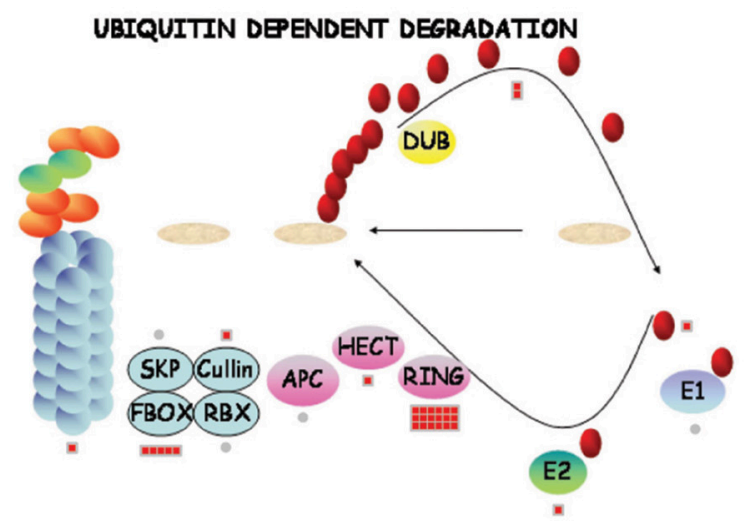

FIGURE 6 | MapMan analysis of genes associated with response to water deficiency. Overviews: (A) Metabolism, (B) Regulation, (C) Transcription, and (D) Proteasome. Red boxes indicate genes up-regulated by stress. Detailed information is presented in Tables S6, S7.

SALT-AND DROUGHT-INDUCED RING FINGER 1 (OsSDIR1) is a candidate gene for engineering drought tolerance in various crop plants. Its expression is also up-regulated by excess $\mathrm{NaCl}$ (Gao et al., 2011). The expression patterns of 47 OsRFP genes in response to abiotic stresses have been monitored via semiquantitative reverse transcription PCR and in silico analysis (Lim et al., 2013). Our results also suggest a strong correlation between drought and activity of RING finger E3 ligase.

\section{Evaluation of Candidate Genes Associated with Drought Stress Using Rice Genes with Known Functions}

To evaluate the significance of our candidate genes, we searched the literature to determine if functions for them have been reported previously. This was accomplished with the online OGRO database, which provides a thorough summary of rice genes that have been characterized through molecular and genetic techniques (Yamamoto et al., 2012). Of the 41 genes found in that database (Table 2), 18 have been linked to various abiotic-stress responses in rice. They include $P h y B$ (Liu J. et al., 2012), OsbZIP52/RISBZ5 (Liu C. et al., 2012), OsETOL1 (Du et al., 2014), trehalose-6-phosphate synthase 1 (OsTPS1; (Li H. W. et al., 2011), OsTZF1 (Jan et al., 2013), and sHSP17.7 (Sato and Yokoya, 2008) for drought; OsCIPK15 (Xiang et al., 2007), OsGAPC3 (Zhang et al., 2011), glyoxalase I (OsGLYI-11.2; Mustafiz et al., 2014), Programmed cell death 5 (OsPDCD5; Yang et al., 2013), OsPLD $\alpha 1$ (Shen et al., 2011) OsTPS1 (Li H. W. et al., 2011), and OsTZF1 (Jan et al., 2013), for salinity; OsbZIP52/RISBZ5 (Liu C. et al., 2012) OsLti6b (Kim et al., 2007), OsTPS1 (Li H. W. et al., 2011), and $v 1$ (Kusumi et al., 2011) for chilling; and ETHYLENE OVERPRODUCER 1-like (OsETOL1) for tolerance to submergence ( $\mathrm{Du}$ et al., 2014; Table 2). These findings indicate that our candidate genes are potentially involved in plant responses to abiotic stress (including drought) and suggest the possibility of crosstalk among related pathways.

\section{Analyses of Predicted Protein-Protein Interactions Associated with Drought Tolerance}

Regulatory genes are primary targets when investigating diverse stress responses and developmental processes. Among the 1,098 genes that were up-regulated by $3 \mathrm{~d}$ of drought treatment, 


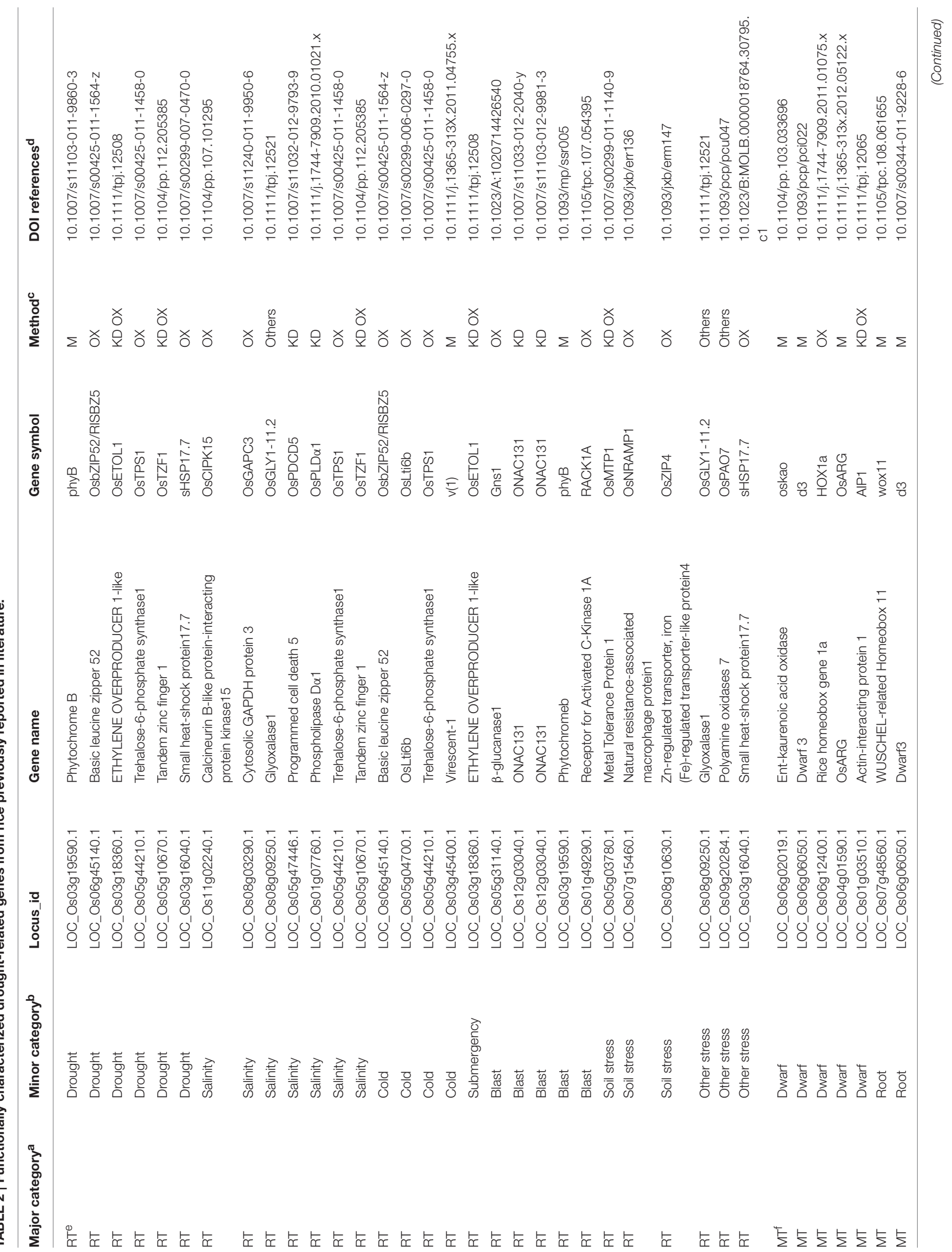




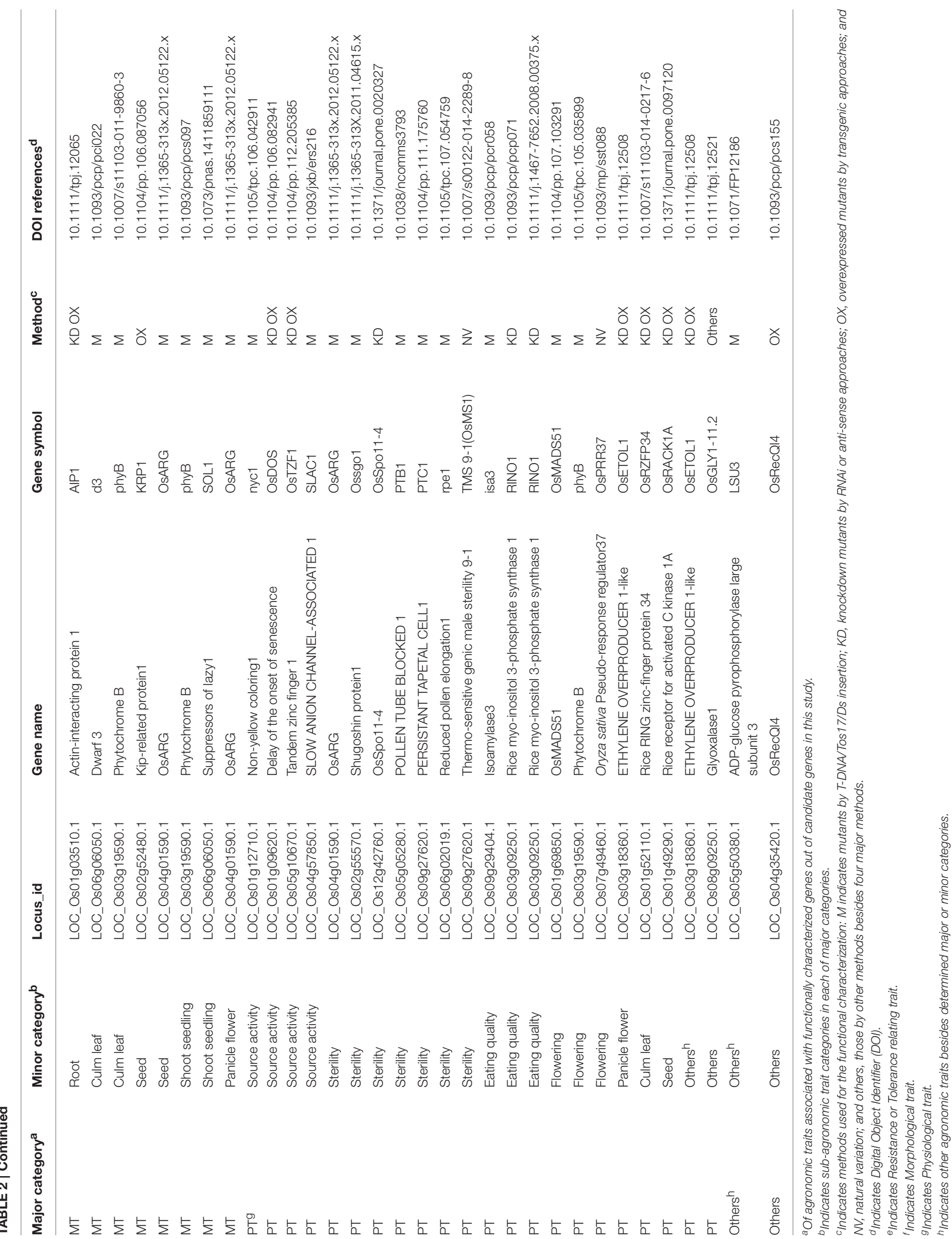


we identified 104 TFs, 44 kinases, 27 transporters, and 40 functionally characterized genes (Figure 7, Table 2, Table S6). Understanding the regulatory relationships among them can improve our ability to develop novel strategies for enhancing plant tolerance to various stresses. To increase our knowledge, we utilized the Rice Interactions Viewer to generate a hypothetical protein-protein interaction network associated with those upregulated genes mentioned above (Ho et al., 2012). Four categories were used as query in the refined network: 10 functionally characterized genes (red lettering in large circles of Figure 7), 12 TFs (large brown circles), four kinases (large yellow circles), and three transporters (large sky-blue circles). We also highlighted elements with multiple interactions among these regulatory and functionally characterized genes. Details about locus IDs, gene names, and putative functions are provided in Table S7.

\section{Drought Tolerance of phyb Mutant through Effective Reactive Oxygen Species (ROS) Scavenging in Roots}

Of the 41 genes with known functions, alleles with TDNA insertions were found for mutants of phytochrome $B$ (phyb)/LOC_Os03g19590 (Figure 7, number 10). As we have reported previously (Liu J. et al., 2012), a drought-tolerant phenotype has been confirmed in 30-d-old greenhouse-grown seedlings of phyb mutant Line 4A-02226, which has a T-DNA insertion in the $3 \mathrm{rd}$ intron (Figures 8A-F). This study informed that drought tolerance in phyb mutant is caused by reduction of stomatal density but not by root morphology. However, in our study, the comparison of dry weight between WT and phyb mutant roots exposed to WD stress for $3 \mathrm{~d}$ revealed that phyb mutant roots have $48.5 \%$ less dry weight than that of WT. More interestingly, after recovery process, WT did not survive and the dry weight of the root was reduced, while phyb mutant survived and the dry weight of roots even increased due to the continuous growth of the roots (Figures $\mathbf{8 G}-\mathbf{J}$ ). This result indicates that root development is very important for the drought stress tolerance and also we are interested in the mechanism how rice roots overcome damage caused by prolonged WD stress. It was known that processing of reactive oxygen species (ROS) play important roles in root development of other plant species (Causin et al., 2012; Zhao et al., 2016).

Several studies have reported a correlation between major active enzyme activity and drought (Huang et al., 2010; Huda et al., 2013; Xu et al., 2016). The enzyme-catalyzed reactions are the main mechanisms for the removal of superoxide and $\mathrm{H}_{2} \mathrm{O}_{2}$. Especially, ascorbate peroxidases (APXs) and catalases (CATs) are known to be important enzymes involved in $\mathrm{H}_{2} \mathrm{O}_{2}$ removal under drought stress (Noctor et al., 2014). Therefore, we analyzed the expression patterns of CAT and APX antioxidant enzyme families using real-time PCR analyses for the samples under normal condition, drought stress condition for $3 \mathrm{~d}$, and recovery after drought stress. As a result, we found that expressions of five of the eight APX genes and one of the three CAT genes were upregulated in $p h y B$ mutant under drought stress, suggesting the major contribution of APX to remove ROSs produced by drought stress in rice roots (Figure 9A). Hydrogen peroxide $\left(\mathrm{H}_{2} \mathrm{O}_{2}\right)$ contents were measured to confirm the accumulation of ROS in the roots of phyb mutant. Subseuently, phyb mutants always maintained high $\mathrm{H}_{2} \mathrm{O}_{2}$ contents compared to wild type and in addition showed the highest $\mathrm{H}_{2} \mathrm{O}_{2}$ contents under drought stress

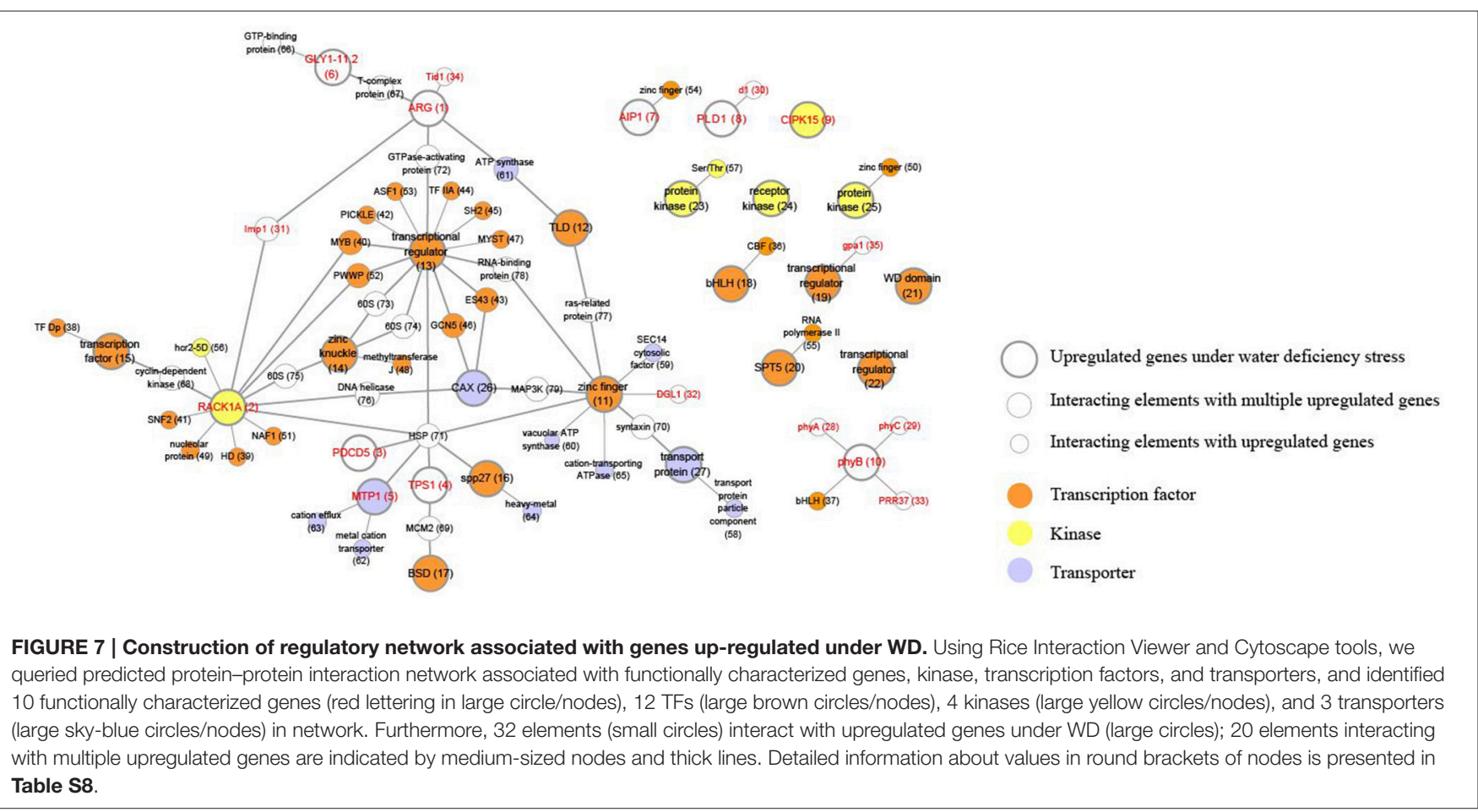




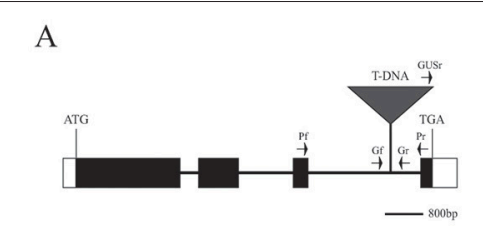

B

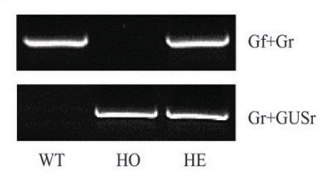

C

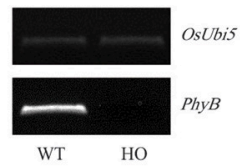

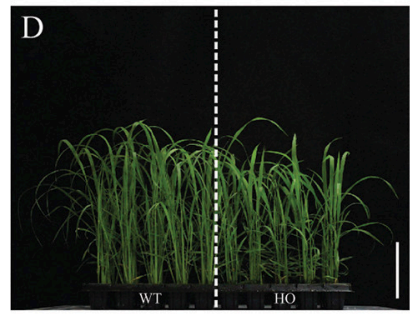

G

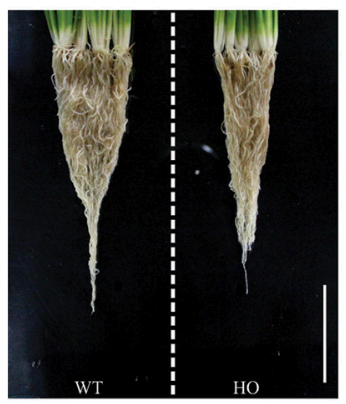

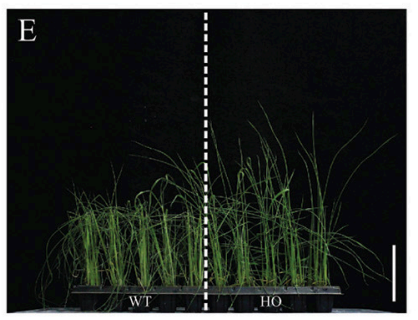

H

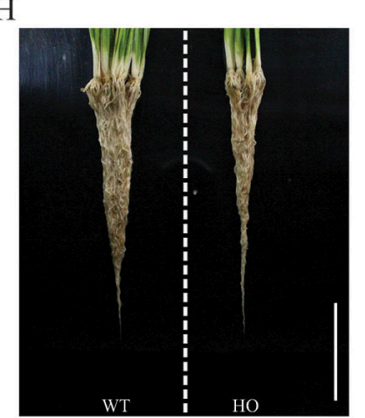

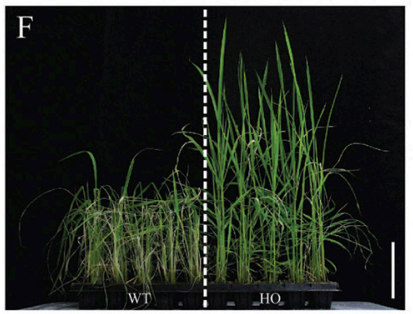

I

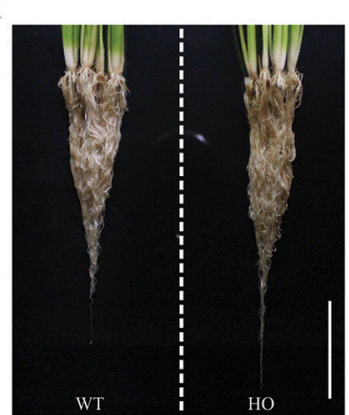

J

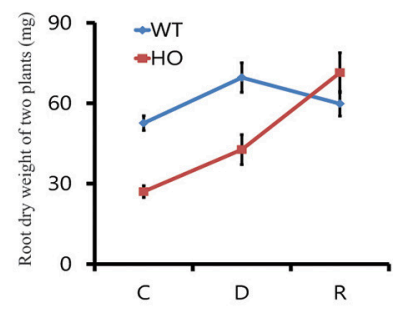

FIGURE 8 | Drought-stress response mediated by PhyB using T-DNA insertional mutant. Schematic diagram for T-DNA insertion site in PhyB of Line 4A-02226 is shown (A). Black boxes represent exons; white boxes, UTR; lines between boxes, introns; gray triangle, T-DNA insertion; small arrows, gene-specific primers for qRT-PCR analysis and genotyping of tagged gene. ATG and TGA indicate start and stop codons. Scale bar $=800$ bp. Genotyping was performed for phyB mutant line (B). Genotyping experiment identified homozygous progenies with T-DNA in PhyB. WT, wild-type segregants of T-DNA insertional line in PhyB; HO, homozygote; HE, heterozygote. Expression of PhyB was significantly suppressed in mutant (C). OsUBI5 (LOC_OsO1g22490) was used as internal control. phyB homozygous progenies with T-DNA insertion demonstrated drought-tolerant phenotype. phyB and wild-type segregants grown in plastic pots for 4 weeks was exposed to water deficiency for $3 \mathrm{~d}$. Photos were taken $7 \mathrm{~d}$ after re-watering (D-F). Scale bar $=10 \mathrm{~cm}$. (G-J) shows the respective roots and dry weight. Scale bar $=$ $5 \mathrm{~cm} . N=3$ for (D-I); $n=100$ for $(\mathbf{J})$.

(Figure 9B). Measurement of APX enzyme activity between phyb mutants and wild type segregants demonstrates that phyb mutants have the better performance of APX activity at drought stress for $3 \mathrm{~d}$ than that of wild type. In addition, the CAT activity of the phyb mutants was consistently higher than that of WT, although it decreased during drought stress rather than normal condition (Figure 9C). Therefore, we estimate that phyb mutant might retain the tolerance to drought stress by effective ROS scavenging in root besides controlling stomatal density in leaf.

\section{DISCUSSION}

\section{RNA-Seq Analysis Using Roots of Rice Plants Grown in Soil under a Limited Moisture Supply Provides Novel Sources for Future Applications to Enhance Drought Tolerance}

Our candidate genes for conferring tolerance to water deficiencies were identified from RNA-Seq transcriptome analysis of root samples from 4-week-old soil-grown rice plants. The samples were well-qualified for transcriptome analysis based on time-course physiological responses of roots under water deficiency and recovery compared to controls as well as expression patterns analysis with marker genes. Our transcriptome data is useful for identifying novel targets for drought tolerance. When RNA-Seq data were compared with public microarray data under drought stress conditions, 32.05\% of those genes (352 of 1,098) showed similar trends in their stress responses (Table S8). However, the others are unique in our experiments, suggesting novel candidate genes for future studies. In addition, the RNA-Seq approach can provide more candidates that cannot be discovered by microarray technology because the latter is able to detect the expression profiles of fixed-target transcripts. In parallel with this description, we did not identify Affymetrix probe IDs for 279 genes (i.e., $25.40 \%$ of the total) of DEGs after $3 \mathrm{~d}$ of drought treatment. By contrast, the most popular array system in rice, Affymetrix array platform, covers $\sim 90 \%$ of the annotated genes in the rice genome (Jung et al., 2008a; Chandran and Jung, 2014). Therefore, unique DEGs under drought treatment in this study might be valuable for future studies and further applications to understand novel regulatory mechanism for drought tolerance responses. 


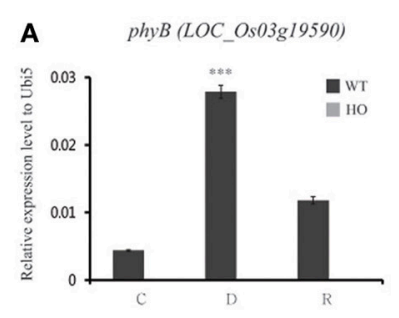

APX5 (LOC_Os12g07830)

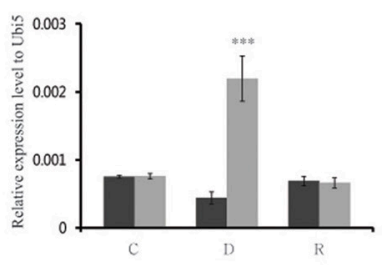

APX2 (LOC_Os07g49400)

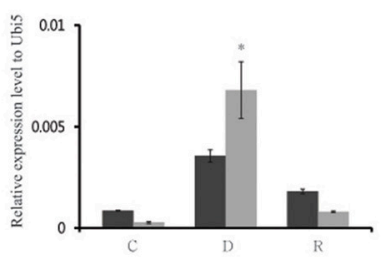

APX8 (LOC_Os02g34810)

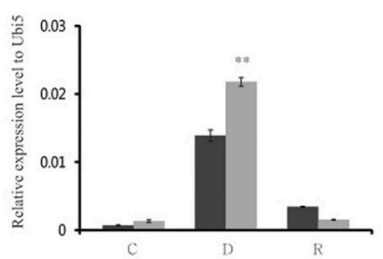

APX3 (LOC_Os04g14680)

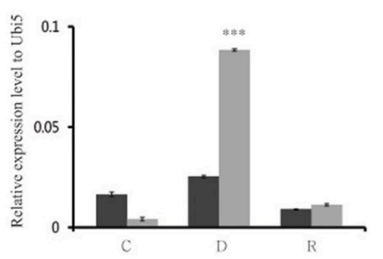

CAT3 (LOC_Os06g51150)
APX4 (LOC_Os08g43560)
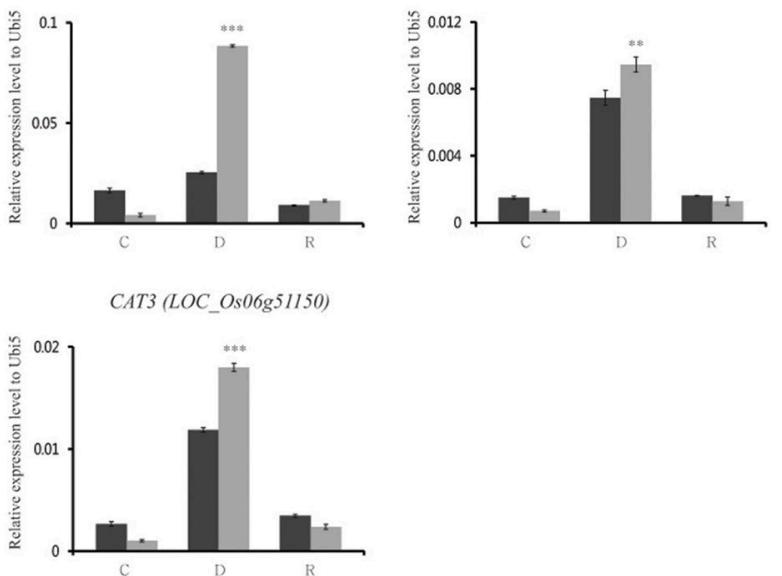

B
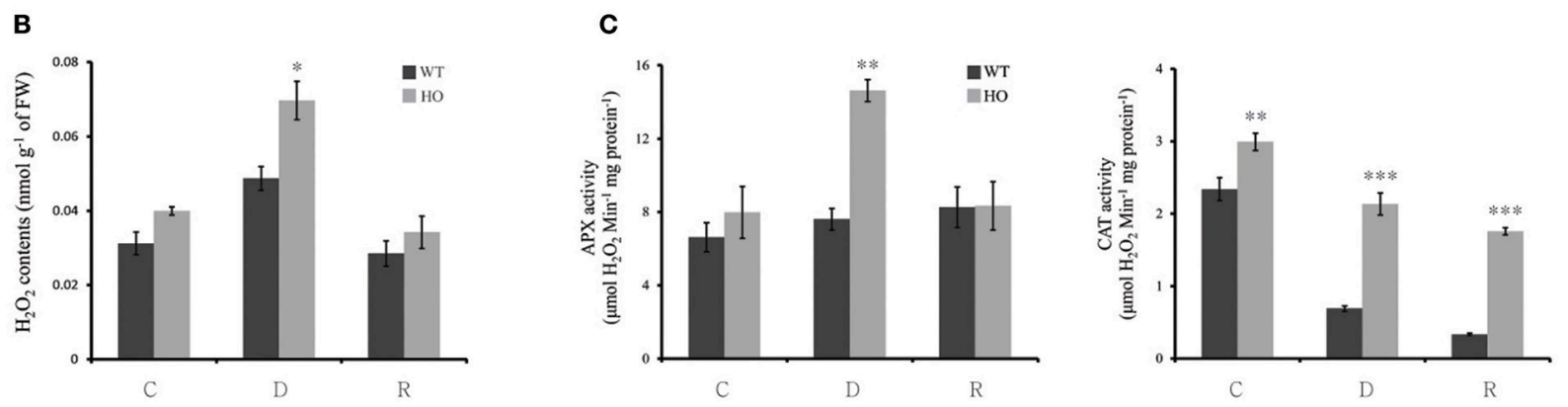

FIGURE 9 | Comparison of transcripts of ROS-relating genes, $\mathrm{H}_{\mathbf{2}} \mathrm{O}_{\mathbf{2}}$ contents, and ROS-scavenging enzymatic activity between WT and phy $B$ mutant. Analyses of transcripts of phyB, APX2, APX3, APX4, APX5, APX8, and CAT3 (A), $\mathrm{H}_{2} \mathrm{O}_{2}$ contents (B) and enzymatic activity of APX and CAT (C) in roots of WT and phyB $(\mathrm{HO})$ mutant under before drought (control), after drought and recovery. The expression levels were normalized to that of Ubi5 using real-time polymerase chain reaction (A). As the biological replicates, we used different three samples. The error bars of the each sample means $\pm S D(n=9)(\mathbf{B}, \mathbf{C})$. WT, wild-type segregants of T-DNA insertional line in PhyB; HO, homozygote; $\mathrm{C}$, control; $\mathrm{D}$, drought treatment for $3 \mathrm{~d}$; $\mathrm{R}$, recovery for $7 \mathrm{~d}$ after drought treatment. ${ }^{\star} P<0.05$; ${ }^{\star \star} P<0.01$; ${ }^{\star \star \star} P<$ 0.001.

\section{In rice root}

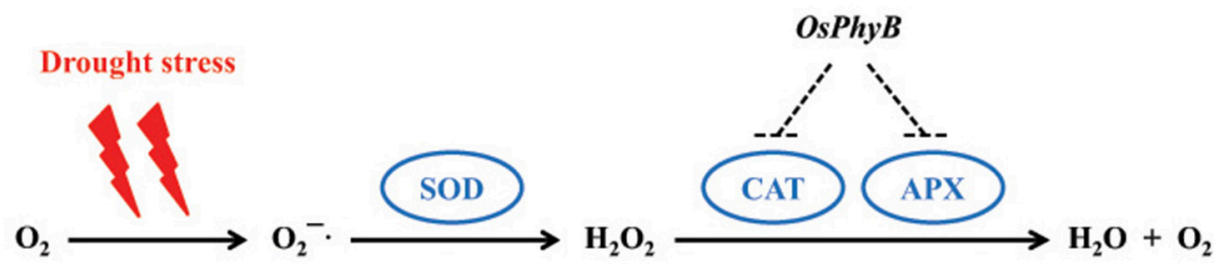

FIGURE 10 | Scavenging model of reactive oxygen species (ROS) in rice roots under drought stresses. APX and CAT, which play a key role in ROS scavenging, are thought to be regulated by phyB.

\section{Drought Stress Might Stimulate Degradation of Primary Metabolites through an Ubiquitin-Mediated Protein Degradation Pathway or via Transcriptional Regulation}

MapMan analysis can reveal a global view of the metabolic pathways associated with the drought-stress response in roots.
Many rice genes in pathways for carbohydrate, cell wall, lipid, and amino acid degradation are stimulated when the water supply is limited, thereby implying that plants use those metabolites and energy resulted from degradation pathways to tolerate stressful growing conditions. For example, a unique $\mathrm{Ni}^{2+}$-dependent and methylglyoxal-inducible GLY I functions in the response and adaptation of rice to abiotic stresses (Mustafiz et al., 2014). The phospholipase $\mathrm{D} \alpha(\mathrm{PLD} \alpha)$ mediates $\mathrm{H}(+)$-ATPase activity and is 
involved in salt tolerance (Shen et al., 2011; see also Figure 6A, Table 2). Therefore, we propose that the ubiquitin-mediated pathway for protein degradation associated with our candidate genes is evidence that F-box E3 ligases or RING box E3 ligases have dominant roles in the process. For example, OsRZFP34 (LOC_Os01g52110), encoding a rice RING zinc-finger protein, is positively involved in the opening of stomata, even under ABA treatment, and might have a potential role in abiotic-stress tolerance (Hsu et al., 2014). Moreover, the D3 (LOC_Os06g06050) gene, encoding an F-box leucine-rich repeat protein orthologous to Arabidopsis MAX2/ORE9, is involved in tillering and shoot-branching (Ishikawa et al., 2005). Our transcriptome data also suggest additional roles in the drought response (Figure 6D, Table 2). Therefore, we believe that many genes within the degradation pathways of primary metabolites, as well as biosynthetic pathways for secondary metabolites, positively influence drought tolerance in rice roots. However, functional elucidation of major, yet uncharacterized, regulatory genes could lead to novel ways for improving the plant response to a water deficiency.

\section{Combining the Protein Interactome with Network Analysis and Incorporation of Mutants Suggests Regulatory Pathways for Tolerating Drought Stress}

In our network analysis, we found that LOC_Os08g39140, encoding heat shock protein 90 (HSP90) in circle 71 of the network, potentially interacts with seven gene products. Among them, four have known functions (i.e., Receptor for Activated C-Kinase 1A, or RACK1A; PDCD5, TPS1, and Metal Tolerance Protein 1, or MTP1) while the others are TFs (Figure 7). Heatshock proteins/chaperones play a crucial role in protecting plants through proteins and membranes stabilization and protein refolding under stress conditions (Wang et al., 2004). Among the products that interact with HSP90, three are related to abiotic-stress responses, indicating significant roles for HSP90. The three include OsPDCD5, involved in salinity (Yang et al., 2013); OsTPS1, involved in drought, salinity, and cold ( $\mathrm{Li} \mathrm{H}$. W. et al., 2011); and OsMTP1, which improves plant tolerance to excess heavy metals such as Zn and Cd (Yuan et al., 2012). In addition, RACK1A functions in the production of ROS and resistance to rice blast infection (Nakashima et al., 2008). One inevitable consequence of drought stress is that more ROS are generated in diverse cellular compartments, e.g., the chloroplasts, peroxisomes, and mitochondria. However, ROS accumulations in response to a water deficiency are tightly controlled by a versatile and cooperative antioxidant system that modulates intracellular ROS concentrations and sets the redoxstatus of a cell (Cruz de Carvalho, 2008). These activities suggest that RACK1A is involved in a ROS-mediating drought-stress pathway.

The three other TFs with important roles in drought tolerance include, first, a zinc finger domain (circle 11 in our network). Overexpression of ZFP36 in rice elevates the activities of antioxidant enzymes and enhances plant tolerance to water and oxidative stresses (Zhang et al., 2014). Second, a loss-of-function mutant of a drought and salt tolerance gene (DST) stimulates stomatal closure and reduce stomatal density, resulting in greater drought and salt tolerance in rice (Huang et al., 2009). Finally, an upstream activation factor (UAF in circle 16) regulates the pace of transcriptional activity by binding to an upstream element of target genes in response to diverse signals (Carthew et al., 1985). Therefore, our network data that integrate this diverse functional information will be useful resources when designing more detailed molecular mechanisms for future applications that can enhance tolerance to a water deficiency.

\section{A Model of Drought Tolerance Mechanism by Modulating Reactive Oxygen Species during Root Development}

Hydrogen peroxide $\left(\mathrm{H}_{2} \mathrm{O}_{2}\right)$ is a signaling molecule involved in the regulation of specific biological and physiological processes and is a relatively stable non-radical ROS. However, abiotic stresses such as drought increase the production of $\mathrm{H}_{2} \mathrm{O}_{2}$ in plants, which can cause serious damage to biomolecules (Slesak et al., 2007). To solve this problem, plants are endowed with $\mathrm{H}_{2} \mathrm{O}_{2}$-metabolizing enzymes, among which CAT and APX play the most important role (Sofo et al., 2015; Li et al., 2016). For example, Panicum sumatrense with strong drought tolerance has been reported to increase the activity of antioxidant enzymes such as CAT and peroxidase during drought stress (Ajithkumar and Panneerselvam, 2014). Olive plants also increase CAT activity in the leaves when water deficit conditions, thereby limiting cellular damage due to ROS (Sofo et al., 2004). As the drought increased in soybeans, a clear increase in the amount and activity of APX was observed and APX2 overexpressing plants in rice showed increased APX activity and improved stress resistance (Kausar et al., 2012; Zhang et al., 2013). These facts support that CAT and APX are antioxidant enzymes that play a key role in recovery from drought stress (Faize et al., 2011; Pinheiro and Chaves, 2011). We confirmed an increase in APX activity in the phyb mutant roots during drought stress. In addition, we observed that phyb mutant had higher CAT activity than WT under any circumstances (Figure 9C).

Despite the higher level of APX and CAT activity, phyb mutants have higher $\mathrm{H}_{2} \mathrm{O}_{2}$ accumulation than wild type plants. One possible explanation on this phenamenum is that rice plants under drought stress might use $\mathrm{H}_{2} \mathrm{O}_{2}$ as a second messenger to trigger ROS removing pathway. It was demonstrated that $\mathrm{H}_{2} \mathrm{O}_{2}$ plays key roles in processing external biotic and abiotic stimuli thorugh signal transduction pathways in plant cells (Petrov and Van Breusegem, 2012). In addition, several reports in rice support the significance of increased $\mathrm{H}_{2} \mathrm{O}_{2}$ in tolerance responses against drought stress: overexpression of abscisic acid, stress, and ripening 5 (OsASR5) gene exhibits a drought resistant phenotype despite higher $\mathrm{H}_{2} \mathrm{O}_{2}$ content under drought stress compared to wild type (Li J. et al., 2011); drought and salt tolerance (dst) mutant has increased stomatal closure and reduced stomatal density due to accumulated $\mathrm{H}_{2} \mathrm{O}_{2}$, consequently resulting in enhanced drought tolerance in rice (Huang et al., 2009); rice similar to 
$R C D$ one (SRO/OsSRO1c) promotes stomatal closure and $\mathrm{H}_{2} \mathrm{O}_{2}$ accumulation via stress-responsive NAC 1 (SNAC1) and DST regulators, resulting in tolerance responses against drought stress (You et al., 2013).

Recent studies indicate that phytochrome influences the growth and development of roots through the role of photoreceptors and their associated signaling mechanisms. For example, in Arabidopsis, light was efficiently conducted through the stems to the roots, resulting in the accumulation of ELOTATED HYPOCOTYL 5 (HY5) protein by photoactivated phyb (Lee et al., 2016). We therefore expect that OsPhyB acts as a negative regulator of APX and CAT activity by a transcription factor or phytochrome interacting factor (PIF) during drought stress in rice roots (Figure 10). Details of this model need to be elucidated through further studies.

\section{AUTHOR CONTRIBUTIONS}

YY, JP, and YG performed the experiments; YY and AN analyzed the data; and YY, SL, GA, and KJ wrote the paper. All authors read and approved the final manuscript.

\section{ACKNOWLEDGMENTS}

This work was supported by a grant from the NextGeneration BioGreen 21 Program (PJ01182602 to KJ), the Rural Development Administration, Republic of Korea.

\section{REFERENCES}

Ajithkumar, I. P., and Panneerselvam, R. (2014). ROS scavenging system, osmotic maintenance, pigment and growth status of Panicum sumatrense roth. Under drought stress. Cell Biochem. Biophys. 68, 587-595. doi: 10.1007/s12013-013-9746-x

Andrews, S. (2010). FastQC: A Quality Control Tool for High Throughput Sequence Data. Available online at: https://www.bioinformatics.babraham.ac. $\mathrm{uk} /$ projects/fastqc/

Bailey, T. L., Williams, N., Misleh, C., and Li, W. W. (2006). MEME: discovering and analyzing DNA and protein sequence motifs. Nucleic Acids Res. 34 (suppl_2), W369-W373. doi: 10.1093/nar/gkl198

Boronat, A., Martínez, M. C., Reina, M., Puigdomènech, P., and Palau, J. (1986). Isolation and sequencing of a $28-\mathrm{kDa}$ glutelin-2 gene from maize. Common elements in the $5^{\prime}$ flanking regions among zein and glutelin genes. Plant Sci. 47, 95-102.

Bowne, J. B., Erwin, T. A., Juttner, J., Schnurbusch, T., Langridge, P., Bacic, A., et al. (2012). Drought responses of leaf tissues from wheat cultivars of differing drought tolerance at the metabolite level. Mol. Plant 5, 418-429. doi: $10.1093 / \mathrm{mp} / \mathrm{ssr} 114$

Boyer, J. S. (1982). Plant productivity and environment. Science 218, 443-448. doi: 10.1126/science.218.4571.443

Cao, P., Jung, K.-H., Choi, D., Hwang, D., Zhu, J., and Ronald, P. C. (2012). The Rice Oligonucleotide Array Database: an atlas of rice gene expression. Rice 5:17. doi: 10.1186/1939-8433-5-17

Carthew, R. W., Chodosh, L. A., and Sharp, P. A. (1985). An RNA polymerase II transcription factor binds to an upstream element in the adenovirus major late promoter. Cell 43, 439-448. doi: 10.1016/0092-8674(85)90174-6

Causin, H. F., Roqueiro, G., Petrillo, E., Láinez, V., Pena, L. B., Marchetti, C. F., et al. (2012). The control of root growth by reactive oxygen species in Salix nigra Marsh. seedlings. Plant Sci. 183, 197-205. doi: 10.1016/j.plantsci.2011.08.012

Chandran, A., and Jung, K.-H. (2014). Resources for systems biology in rice. J. Plant Biol. 57, 80-92. doi: 10.1007/s12374-014-0903-6

\section{SUPPLEMENTARY MATERIAL}

The Supplementary Material for this article can be found online at: http://journal.frontiersin.org/article/10.3389/fpls.2017. 00580/full\#supplementary-material

Table S1 | Primer sequences used for genotype and qRT-PCR analyses.

Table S2 | Names and related RNA-Seq data for genes differentially expressed in response to $2 \mathrm{~d}$ of water deficiency (WD) vs. well-watered control (C).

Table S3 | Names and related RNA-Seq data for genes differentially expressed in response to $3 \mathrm{~d}$ of water deficiency (WD) vs. well-watered control (C).

Table S4 | Gene Ontology (GO) assignment in "biological process" category for genes up-regulated by $3 \mathrm{~d}$ of WD treatment.

Table S5 | Overview of MapMan terms assigned to genes up-regulated by $3 \mathrm{~d}$ of WD treatment.

Table S6 | Detailed information about MapMan terms assigned to genes up-regulated by $3 \mathrm{~d}$ of WD treatment.

Table S7 | Detailed information from analyses of protein-protein interactions for drought-stress response in Figure 7.

Table S8 | Comparison of microarray data (GSE26280) and RNA-Seq data for roots from drought-stressed rice plants.

Figure S1 | Number of upregulated and downregulated genes identified from comparisons between roots of plants exposed for $\mathbf{2}$ or $\mathbf{3} \mathrm{d}$ to WD treatment and corresponding well-watered controls.

Figure S2 | Validation of two water deficiency-induced genes [(A); LOC_Os04g52290 and (B); LOC_Os07g02710] revealed by promoter trap system and GUS assays.

Chandran, A. K. N., Lee, G.-S., Yoo, Y.-H., Yoon, U.-H., Ahn, B.-O., Yun, D.-W., et al. (2016). Functional classification of rice flanking sequence tagged genes using MapMan terms and global understanding on metabolic and regulatory pathways affected by dxr mutant having defects in light response. Rice 9, 17. doi: 10.1186/s12284-016-0089-2

Chang, W.-C., Lee, T.-Y., Huang, H.-D., Huang, H.-Y., and Pan, R.-L. (2008) PlantPAN: plant promoter analysis navigator, for identifying combinatorial cis-regulatory elements with distance constraint in plant gene groups. BMC Genomics 9:561. doi: 10.1186/1471-2164-9-561

Charlton, A. J., Donarski, J. A., Harrison, M., Jones, S. A., Godward, J., Oehlschlager, S., et al. (2008). Responses of the pea (Pisum sativum L.) leaf metabolome to drought stress assessed by nuclear magnetic resonance spectroscopy. Metabolomics 4, 312-327. doi: 10.1007/s11306-008-0128-0

Chen, H., Chen, W., Zhou, J., He, H., Chen, L., Chen, H., et al. (2012). Basic leucine zipper transcription factor OsbZIP16 positively regulates drought resistance in rice. Plant Sci. 193-194, 8-17. doi: 10.1016/j.plantsci.2012.05.003

Chen, J. Q., Meng, X. P., Zhang, Y., Xia, M., and Wang, X. P. (2008). Overexpression of OsDREB genes lead to enhanced drought tolerance in rice. Biotechnol. Lett. 30, 2191-2198. doi: 10.1007/s10529-008-9811-5

Cruz de Carvalho, M. H. (2008). Drought stress and reactive oxygen species: production, scavenging and signaling. Plant Signal. Behav. 3, 156-165. doi: $10.4161 /$ psb.3.3.5536

Cui, M., Zhang, W., Zhang, Q., Xu, Z., Zhu, Z., Duan, F., et al. (2011). Induced over-expression of the transcription factor OsDREB2A improves drought tolerance in rice. Plant Physiol. Biochem. 49, 1384-1391. doi: 10.1016/j.plaphy.2011.09.012

Daszkowska-Golec, A., and Szarejko, I. (2013). Open or close the gate - stomata action under the control of phytohormones in drought stress conditions. Front. Plant Sci. 4:138. doi: 10.3389/fpls.2013.00138

Du, H., Wu, N., Cui, F., You, L., Li, X., and Xiong, L. (2014). A homolog of ETHYLENE OVERPRODUCER, OsETOL1, differentially modulates drought and submergence tolerance in rice. Plant J. 78, 834-849. doi: 10.1111/tpj. 12508 
Dubouzet, J. G., Sakuma, Y., Ito, Y., Kasuga, M., Dubouzet, E. G., Miura, S., et al. (2003). OsDREB genes in rice, Oryza sativa L., encode transcription activators that function in drought-, high-salt- and cold-responsive gene expression. Plant J. 33, 751-763. doi: 10.1046/j.1365-313X.2003.01661.x

Faize, M., Burgos, L., Faize, L., Piqueras, A., Nicolas, E., Barba-Espin, G., et al. (2011). Involvement of cytosolic ascorbate peroxidase and $\mathrm{Cu} / \mathrm{Zn}$-superoxide dismutase for improved tolerance against drought stress. J. Exp. Bot. 62, 2599-2613. doi: 10.1093/jxb/erq432

Franco-Zorrilla, J. M., López-Vidriero, I., Carrasco, J. L., Godoy, M., Vera, P., and Solano, R. (2014). DNA-binding specificities of plant transcription factors and their potential to define target genes. Proc. Natl. Acad. Sci. U.S.A. 111, 2367-2372. doi: 10.1073/pnas.1316278111

Gao, T., Wu, Y., Zhang, Y., Liu, L., Ning, Y., Wang, D., et al. (2011). OsSDIR1 overexpression greatly improves drought tolerance in transgenic rice. Plant Mol. Biol. 76, 145-156. doi: 10.1007/s11103-011-9775-z

Garg, B., Jaiswal, J. P., Misra, S., Tripathi, B. N., and Prasad, M. (2012). A comprehensive study on dehydration-induced antioxidative responses during germination of Indian bread wheat (Triticum aestivum L. em Thell) cultivars collected from different agroclimatic zones. Physiol. Mol. Biol. Plants 18, 217-228. doi: 10.1007/s12298-012-0117-7

Hirayama, T., Ohto, C., Mizoguchi, T., and Shinozaki, K. (1995). A gene encoding a phosphatidylinositol-specific phospholipase $\mathrm{C}$ is induced by dehydration and salt stress in Arabidopsis thaliana. Proc. Natl. Acad. Sci. U.S.A. 92, 3903-3907. doi: 10.1073/pnas.92.9.3903

Ho, C.-L., Wu, Y., Shen, H., Provart, N. J., and Geisler, M. (2012). A predicted protein interactome for rice. Rice 5:15. doi: 10.1186/1939-8433-5-15

Hsu, K. H., Liu, C. C., Wu, S. J., Kuo, Y. Y., Lu, C. A., Wu, C. R., et al. (2014). Expression of a gene encoding a rice RING zinc-finger protein, OsRZFP34, enhances stomata opening. Plant Mol. Biol. 86, 125-137. doi: 10.1007/s11103-014-0217-6

Huang, X. Y., Chao, D. Y., Gao, J. P., Zhu, M. Z., Shi, M., and Lin, H. X. (2009). A previously unknown zinc finger protein, DST, regulates drought and salt tolerance in rice via stomatal aperture control. Genes Dev. 23, 1805-1817. doi: $10.1101 /$ gad.1812409

Huang, X.-S., Liu, J.-H., and Chen, X.-J. (2010). Overexpression of PtrABF gene, a bZIP transcription factor isolated from Poncirus trifoliata, enhances dehydration and drought tolerance in tobacco via scavenging ROS and modulating expression of stress-responsive genes. BMC Plant Biol. 10:230. doi: 10.1186/1471-2229-10-230

Huda, K. M. K., Banu, M. S. A., Garg, B., Tula, S., Tuteja, R., and Tuteja, N. (2013). OsACA6, a P-type IIB $\mathrm{Ca}^{2+}$ ATPase promotes salinity and drought stress tolerance in tobacco by ROS scavenging and enhancing the expression of stress-responsive genes. Plant J. 76, 997-1015. doi: 10.1111/tpj. 12352

Ishikawa, S., Maekawa, M., Arite, T., Onishi, K., Takamure, I., and Kyozuka, J. (2005). Suppression of tiller bud activity in tillering dwarf mutants of rice. Plant Cell Physiol. 46, 79-86. doi: 10.1093/pcp/pci022

Jain, M., Nijhawan, A., Tyagi, A. K., and Khurana, J. P. (2006). Validation of housekeeping genes as internal control for studying gene expression in rice by quantitative real-time PCR. Biochem. Biophys. Res. Commun. 345, 646-651. doi: 10.1016/j.bbrc.2006.04.140

Jan, A., Maruyama, K., Todaka, D., Kidokoro, S., Abo, M., Yoshimura, E., et al. (2013). OsTZF1, a CCCH-tandem zinc finger protein, confers delayed senescence and stress tolerance in rice by regulating stress-related genes. Plant Physiol. 161, 1202-1216. doi: 10.1104/pp.112.205385

Jeon, J. S., Lee, S., Jung, K. H., Jun, S. H., Jeong, D. H., Lee, J., et al. (2000). T-DNA insertional mutagenesis for functional genomics in rice. Plant J. 22, 561-570. doi: 10.1046/j.1365-313x.2000.00767.x

Jeong, D. H., An, S., Kang, H.-G., Moon, S., Han, J.-J., Park, S., et al. (2002). TDNA insertional mutagenesis for activation tagging in rice. Plant Physiol. 130, 1636-1644. doi: 10.1104/pp.014357

Jeong, H. J., and Jung, K. H. (2015). Rice tissue-specific promoters and conditiondependent promoters for effective translational application. J. Integr. Plant Biol. 57, 913-924. doi: 10.1111/jipb.12362

Jeong, J. S., Kim, Y. S., Baek, K. H., Jung, H., Ha, S.-H., Do Choi, Y., et al. (2010). Root-specific expression of OsNAC10 improves drought tolerance and grain yield in rice under field drought conditions. Plant Physiol. 153, 185-197. doi: $10.1104 /$ pp. 110.154773
Jung, K. H., and An, G. (2012). Application of mapman and ricenet drives systematic analyses of the early heat stress transcriptome in rice seedlings. J. Plant Biol. 55, 436-449. doi: 10.1007/s12374-012-0270-0

Jung, K. H., An, G., and Ronald, P. C. (2008a). Towards a better bowl of rice: assigning function to tens of thousands of rice genes. Nat. Rev. Genet. 9, 91-101. doi: $10.1038 / \mathrm{nrm} 2343$

Jung, K. H., Dardick, C., Bartley, L. E., Cao, P., Phetsom, J., Canlas, P., et al. (2008b). Refinement of light-responsive transcript lists using rice oligonucleotide arrays: evaluation of gene-redundancy. PLOS ONE 3:e3337. doi: 10.1371/journal.pone.0003337

Jung, K.-H., Han, M.-J., Lee, D., Lee, Y.-S., Schreiber, L., Franke, R., et al. (2006). Wax-deficient anther 1 is involved in cuticle and wax production in rice anther walls and is required for pollen development. Plant Cell 18, 3015-3032. doi: 10.1105/tpc.106.042044

Jung, K.-H., Han, M.-J., Lee, Y.-S., Kim, Y.-W., Hwang, I., Kim, M.-J., et al. (2005). Rice Undeveloped Tapetum1 is a major regulator of early tapetum development. Plant Cell 17, 2705-2722. doi: 10.1105/tpc.105.034090

Jung, K.-H., Kim, S.-R., Giong, H.-K., Nguyen, M. X., Koh, H.-J., and An, G. (2015). Genome-wide identification and functional analysis of genes expressed ubiquitously in rice. Mol. Plant 8, 276-289. doi: 10.1016/j.molp.2014.10.013

Kausar, R., Hossain, Z., Makino, T., and Komatsu, S. (2012). Characterization of ascorbate peroxidase in soybean under flooding and drought stresses. Mol. Biol. Rep. 39, 10573-10579. doi: 10.1007/s11033-012-1945-9

Kawahara, Y., de la Bastide, M., Hamilton, J. P., Kanamori, H., McCombie, W. R., Ouyang, S., et al. (2013). Improvement of the Oryza sativa Nipponbare reference genome using next generation sequence and optical map data. Rice 6:4. doi: 10.1186/1939-8433-6-4

Kim, S. H., Kim, J. Y., Kim, S. J., An, K. S., An, G., and Kim, S. R. (2007). Isolation of cold stress-responsive genes in the reproductive organs, and characterization of the OsLti6b gene from rice (Oryza sativa L.). Plant Cell Rep. 26, 1097-1110. doi: 10.1007/s00299-006-0297-0

Krueger, F. (2012). Trim Galore! Available online at: https://www.bioinformatics. babraham.ac.uk/projects/trim_galore/

Kusumi, K., Sakata, C., Nakamura, T., Kawasaki, S., Yoshimura, A., and Iba, K. (2011). A plastid protein NUS1 is essential for build-up of the genetic system for early chloroplast development under cold stress conditions. Plant J. 68, 1039-1050. doi: 10.1111/j.1365-313X.2011.04755.x

Lee, H.-J., Ha, J.-H., Kim, S.-G., Choi, H.-K., Kim, Z. H., Han, Y.-J., et al. (2016). Stem-piped light activates phytochrome B to trigger light responses in Arabidopsis thaliana roots. Sci. Signal. 9, ra106. doi: 10.1126/scisignal.aaf6530

Li, H. W., Zang, B. S., Deng, X. W., and Wang, X. P. (2011). Overexpression of the trehalose-6-phosphate synthase gene OsTPS1 enhances abiotic stress tolerance in rice. Planta 234, 1007-1018. doi: 10.1007/s00425-011-1458-0

Li, J., Li, Y., Yin, Z., Jiang, J., Zhang, M., Guo, X., et al. (2011). OsASR5 enhances drought tolerance through a stomatal closure pathway associated with ABA and $\mathrm{H}_{2} \mathrm{O}_{2}$ signalling in rice. Plant Biotechnol. J. 15, 183-196. doi: 10.1111/pbi.12601

Li, X., Xu, Q., Liao, W., Ma, Z., Xu, X., Wang, M., et al. (2016). Hydrogen peroxide is involved in abscisic acid-induced adventitious rooting in cucumber (Cucumis sativus L.) under drought stress. J. Plant Biol. 59, 536-548. doi: 10.1007/s12374-016-0036-1

Lim, S. D., Hwang, J. G., Jung, C. G., Hwang, S. G., Moon, J. C., and Jang, C. S. (2013). Comprehensive analysis of the rice RING E3 ligase family reveals their functional diversity in response to abiotic stress. DNA Res. 20, 299-314. doi: 10.1093/dnares/dst011

Liu, C., Mao, B., Ou, S., Wang, W., Liu, L., Wu, Y., et al. (2014). OsbZIP71, a bZIP transcription factor, confers salinity and drought tolerance in rice. Plant Mol. Biol. 84, 19-36. doi: 10.1007/s11103-013-0115-3

Liu, C., Wu, Y., and Wang, X. (2012). BZIP transcription factor OsbZIP52/RISBZ5: a potential negative regulator of cold and drought stress response in rice. Planta 235, 1157-1169. doi: 10.1007/s00425-011-1564-Z

Liu, J., Zhang, F., Zhou, J., Chen, F., Wang, B., and Xie, X. (2012). Phytochrome B control of total leaf area and stomatal density affects drought tolerance in rice. Plant Mol. Biol. 78, 289-300. doi: 10.1007/s11103-011-9860-3

Lu, G., Gao, C., Zheng, X., and Han, B. (2009). Identification of OsbZIP72 as a positive regulator of ABA response and drought tolerance in rice. Planta 229, 605-615. doi: 10.1007/s00425-008-0857-3

Martin, M. (2011). Cutadapt removes adapter sequences from high-throughput sequencing reads. EMBnet.journal 17, 10-12. doi: 10.14806/ej.17.1.200 
Mathelier, A., Zhao, X., Zhang, A. W., Parcy, F., Worsley-Hunt, R., Arenillas, D. J., et al. (2014). JASPAR 2014: an extensively expanded and updated openaccess database of transcription factor binding profiles. Nucleic Acids Res. 42, D142-D147. doi: 10.1093/nar/gkt997

Matsukura, S., Mizoi, J., Yoshida, T., Todaka, D., Ito, Y., Maruyama, K., et al. (2010). Comprehensive analysis of rice DREB2-type genes that encode transcription factors involved in the expression of abiotic stress-responsive genes. Mol. Genet. Genomics 283, 185-196. doi: 10.1007/s00438-009-0506-y

Mizoi, J., Shinozaki, K., and Yamaguchi-Shinozaki, K. (2012). AP2/ERF family transcription factors in plant abiotic stress responses. Biochim. Biophys. Acta 1819, 86-96. doi: 10.1016/j.bbagrm.2011.08.004

Mustafiz, A., Ghosh, A., Tripathi, A. K., Kaur, C., Ganguly, A. K., Bhavesh, N. S., et al. (2014). A unique $\mathrm{Ni}^{2+}$-dependent and methylglyoxal-inducible rice glyoxalase i possesses a single active site and functions in abiotic stress response. Plant J. 78, 951-963. doi: 10.1111/tpj.12521

Nakashima, A., Chen, L., Thao, N. P., Fujiwara, M., Wong, H. L., Kuwano, M., et al. (2008). RACK1 functions in rice innate immunity by interacting with the Racl immune complex. Plant Cell 20, 2265-2279. doi: 10.1105/tpc.107.054395

Ning, Y., Jantasuriyarat, C., Zhao, Q., Zhang, H., Chen, S., Liu, J., et al. (2011). The SINA E3 ligase OsDIS1 negatively regulates drought response in rice. Plant Physiol. 157, 242-255. doi: 10.1104/pp.111.180893

Noctor, G., Mhamdi, A., and Foyer, C. H. (2014). The roles of reactive oxygen metabolism in drought: not so cut and dried. Plant Physiol. 164, 1636-1648. doi: $10.1104 /$ pp. 113.233478

Ouyang, S., Zhu, W., Hamilton, J., Lin, H., Campbell, M., Childs, K., et al. (2007). The TIGR rice genome annotation resource: improvements and new features. Nucleic Acids Res. 35 (suppl_1), D883-D887. doi: 10.1093/nar/gkl976

Pandey, S., Bhandari, H., Ding, S., Prapertchob, P., Sharan, R., Naik, D., et al. (2007). Coping with drought in rice farming in Asia: insights from a cross-country comparative study. Agric. Econ. 37, 213-224. doi: 10.1111/j.1574-0862.2007.00246.x

Pasquali, G., Biricolti, S., Locatelli, F., Baldoni, E., and Mattana, M. (2008). Osmyb4 expression improves adaptive responses to drought and cold stress in transgenic apples. Plant Cell Rep. 27, 1677-1686. doi: 10.1007/s00299-008-0587-9

Petrov, V. D., and Van Breusegem, F. (2012). Hydrogen peroxide-a central hub for information flow in plant cells. AoB Plants 2012:pls014. doi: 10.1093/aobpla/pls014

Pinheiro, C., and Chaves, M. M. (2011). Photosynthesis and drought: can we make metabolic connections from available data? J. Exp. Bot. 62, 869-882. doi: $10.1093 / \mathrm{jxb} / \mathrm{erq} 340$

Rapala-Kozik, M., Wolak, N., Kujda, M., and Banas, A. K. (2012). The upregulation of thiamine (vitamin $\mathrm{B}_{1}$ ) biosynthesis in Arabidopsis thaliana seedlings under salt and osmotic stress conditions is mediated by abscisic acid at the early stages of this stress response. BMC Plant Biol. 12:2. doi: 10.1186/14712229-12-2

Rerksiri, W., Zhang, X., Xiong, H., and Chen, X. (2013). Expression and promoter analysis of six heat stress-inducible genes in rice. Sci. World J. 2013:397401. doi: $10.1155 / 2013 / 397401$

Sato, Y., and Yokoya, S. (2008). Enhanced tolerance to drought stress in transgenic rice plants overexpressing a small heat-shock protein, sHSP17.7. Plant Cell Rep. 27, 329-334. doi: 10.1007/s00299-007-0470-0

Shannon, P., Markiel, A., Ozier, O., Baliga, N. S., Wang, J. T., Ramage, D., et al. (2003). Cytoscape: a software environment for integrated models of biomolecular interaction networks. Genome Res. 13, 2498-2504. doi: $10.1101 /$ gr. 1239303

Shen, P., Wang, R., Jing, W., and Zhang, W. (2011). Rice phospholipase D $\alpha$ is involved in salt tolerance by the mediation of $\mathrm{H}^{(+)}$-ATPase activity and transcription. J. Integr. Plant Biol. 53, 289-299. doi: 10.1111/j.1744-7909.2010. 01021.x

Slesak, I., Libik, M., Karpinska, B., Karpinski, S., and Miszalski, Z. (2007). The role of hydrogen peroxide in regulation of plant metabolism and cellular signalling in response to environmental stresses. Acta Biochim. Pol. 54, 39-50.

Sofo, A., Dichio, B., Xiloyannis, C., and Masia, A. (2004). Effects of different irradiance levels on some antioxidant enzymes and on malondialdehyde content during rewatering in olive tree. Plant Sci. 166, 293-302. doi: $10.1016 /$ j.plantsci.2003.09.018
Sofo, A., Scopa, A., Nuzzaci, M., and Vitti, A. (2015). Ascorbate peroxidase and catalase activities and their genetic regulation in plants subjected to drought and salinity stresses. Int. J. Mol. Sci. 16, 13561-13578. doi: 10.3390/ijms160613561

Tang, N., Zhang, H., Li, X., Xiao, J., and Xiong, L. (2012). Constitutive activation of transcription factor OsbZIP46 improves drought tolerance in rice. Plant Physiol. 158, 1755-1768. doi: 10.1104/pp.111.190389

Tao, Z., Kou, Y., Liu, H., Li, X., Xiao, J., and Wang, S. (2011). OsWRKY45 alleles play different roles in abscisic acid signalling and salt stress tolerance but similar roles in drought and cold tolerance in rice. J. Exp. Bot. 62, 4863-4874. doi: $10.1093 / \mathrm{jxb} / \mathrm{err} 144$

Trapnell, C., Hendrickson, D. G., Sauvageau, M., Goff, L., Rinn, J. L., and Pachter, L. (2013). Differential analysis of gene regulation at transcript resolution with RNA-seq. Nat. Biotechnol. 31, 46-53. doi: 10.1038/nbt.2450

Uga, Y., Sugimoto, K., Ogawa, S., Rane, J., Ishitani, M., Hara, N., et al. (2013). Control of root system architecture by DEEPER ROOTING 1 increases rice yield under drought conditions. Nat. Genet. 45, 1097-1102. doi: $10.1038 /$ ng. 2725

Urbanczyk-Wochniak, E., Usadel, B., Thimm, O., Nunes-Nesi, A., Carrari, F., Davy, M., et al. (2006). Conversion of MapMan to allow the analysis of transcript data from Solanaceous species: effects of genetic and environmental alterations in energy metabolism in the leaf. Plant Mol. Biol. 60, 773-792. doi: 10.1007/s11103-005-5772-4

Usadel, B., Nagel, A., Thimm, O., Redestig, H., Blaesing, O. E., Palacios-Rojas, N., et al. (2005). Extension of the visualization tool MapMan to allow statistical analysis of arrays, display of corresponding genes, and comparison with known responses. Plant Physiol. 138, 1195-1204. doi: 10.1104/pp.105. 060459

Vannini, C., Campa, M., Iriti, M., Genga, A., Faoro, F., Carravieri, S., et al. (2007). Evaluation of transgenic tomato plants ectopically expressing the rice Osmyb4 gene. Plant Sci. 173, 231-239. doi: 10.1016/j.plantsci.2007.05.007

Venuprasad, R., Lafitte, H. R., and Atlin, G. N. (2007). Response to direct selection for grain yield under drought stress in rice. Crop Sci. 47, 285-293. doi: 10.2135/cropsci2006.03.0181

Wang, D., Pan, Y., Zhao, X., Zhu, L., Fu, B., and Li, Z. (2011). Genome-wide temporal-spatial gene expression profiling of drought responsiveness in rice. BMC Genomics 12:149. doi: 10.1186/1471-2164-12-149

Wang, Q., Guan, Y., Wu, Y., Chen, H., Chen, F., and Chu, C. (2008). Overexpression of a rice OsDREB1F gene increases salt, drought, and low temperature tolerance in both Arabidopsis and rice. Plant Mol. Biol. 67, 589-602. doi: 10.1007/s11103-008-9340-6

Wang, W., Vinocur, B., Shoseyov, O., and Altman, A. (2004). Role of plant heatshock proteins and molecular chaperones in the abiotic stress response. Trends Plant Sci. 9, 244-252. doi: 10.1016/j.tplants.2004.03.006

Wang, X., Zhang, W., Li, W., and Mishra, G. (2007). "Chapter 8: Phospholipid signaling in plant response to drought and salt stress," in Advances in Molecular Breeding Toward Drought and Salt Tolerant Crops, eds M. A. Jenks, P. M. Hasegawa, and S. M. Jain (Dordrecht: Springer), 183-192.

Wu, X., Shiroto, Y., Kishitani, S., Ito, Y., and Toriyama, K. (2009). Enhanced heat and drought tolerance in transgenic rice seedlings overexpressing OsWRKY11 under the control of HSP101 promoter. Plant Cell Rep. 28, 21-30. doi: 10.1007/s00299-008-0614-x

Xiang, Y., Huang, Y., and Xiong, L. (2007). Characterization of stress-responsive CIPK genes in rice for stress tolerance improvement. Plant Physiol 144, 1416-1428. doi: 10.1104/pp.107.101295

Xiang, Y., Tang, N., Du, H., Ye, H., and Xiong, L. (2008). Characterization of OsbZIP23 as a key player of the basic leucine zipper transcription factor family for conferring abscisic acid sensitivity and salinity and drought tolerance in rice. Plant Physiol. 148, 1938-1952. doi: 10.1104/pp.108.128199

Xiong, H., Li, J., Liu, P., Duan, J., Zhao, Y., Guo, X., et al. (2014). Overexpression of OsMYB48-1, a novel MYB-related transcription factor, enhances drought and salinity tolerance in rice. PLoS ONE 9:e92913. doi: 10.1371/journal.pone.0092913

Xu, Y., Burgess, P., Zhang, X., and Huang, B. (2016). Enhancing cytokinin synthesis by overexpressing ipt alleviated drought inhibition of root growth through activating ROS-scavenging systems in Agrostis stolonifera. J. Exp. Bot. 67, 1979-1992. doi: 10.1093/jxb/erw019 
Yamamoto, E., Yonemaru, J., Yamamoto, T., and Yano, M. (2012). OGRO: the overview of functionally characterized genes in rice online database. Rice 5:26. doi: 10.1186/1939-8433-5-26

Yang, A., Dai, X., and Zhang, W. H. (2012). A R2R3-type MYB gene, OsMYB2, is involved in salt, cold, and dehydration tolerance in rice. J. Exp. Bot. 63, 2541-2556. doi: 10.1093/jxb/err431

Yang, M., Sun, F., Wang, S., Qi, W., Wang, Q., Dong, X., et al. (2013). Down-regulation of OsPDCD5, a homolog of the mammalian PDCD5, increases rice tolerance to salt stress. Mol. Breed. 31, 333-346. doi: 10.1007/s11032-012-9793-9

Yin, X. M., Huang, L. F., Zhang, X., Wang, M. L., Xu, G. Y., and Xia, X. J. (2015). OsCML4 improves drought tolerance through scavenging of reactive oxygen species in rice. J. Plant Biol. 58, 68-73. doi: 10.1007/s12374-014-0349-x

You, J., Zong, W., Li, X., Ning, J., Hu, H., and Li, X., et al. (2013). The SNAC1-targeted gene OsSRO1c modulates stomatal closure and oxidative stress tolerance by regulating hydrogen peroxide in rice. J. Exp. Bot. 64, 569-583. doi: 10.1093/jxb/ers349

Yuan, L., Yang, S., Liu, B., Zhang, M., and Wu, K. (2012). Molecular characterization of a rice metal tolerance protein, OsMTP1. Plant Cell Rep. 31, 67-79. doi: 10.1007/s00299-011-1140-9

Zang, Q.-W., Wang, C.-X., Li, X.-Y., Guo, Z.-A., Jing, R.-L., Zhao, J., et al. (2010). Isolation and characterization of a gene encoding a polyethylene glycol-induced cysteine protease in common wheat. J. Biosci. 35, 379-388. doi: 10.1007/s12038-010-0043-1

Zhang, H., Liu, Y., Wen, F., Yao, D., Wang, L., Guo, J., et al. (2014). A novel rice $\mathrm{C} 2 \mathrm{H} 2$-type zinc finger protein, ZFP36, is a key player involved in abscisic acidinduced antioxidant defence and oxidative stress tolerance in rice. J. Exp. Bot. 65, 5795-5809. doi: 10.1093/jxb/eru313

Zhang, X., Zhang, B., Li, M., Yin, X., Huang, L., Cui, Y., et al. (2016). OsMSR15 encoding a rice $\mathrm{C} 2 \mathrm{H} 2$-type zinc finger protein confers enhanced drought tolerance in transgenic Arabidopsis. J. Plant Biol. 59, 271-281. doi: 10.1007/s12374-016-0539-9

Zhang, X. H., Rao, X. L., Shi, H. T., Li, R. J., and Lu, Y. T. (2011). Overexpression of a cytosolic glyceraldehyde-3-phosphate dehydrogenase gene OsGAPC3 confers salt tolerance in rice. Plant Cell. Tissue Organ Cult. 107, 1-11. doi: 10.1007/s11240-011-9950-6

Zhang, Z., Zhang, Q., Wu, J., Zheng, X., Zheng, S., Sun, X., et al. (2013). Gene knockout study reveals that cytosolic ascorbate peroxidase 2(OsAPX2) plays a critical role in growth and reproduction in rice under drought, salt and cold Stresses. PLOS ONE 8:e57472. doi: 10.1371/journal.pone. 0057472

Zhao, L., Hu, Y., Chong, K., and Wang, T. (2010). ARAG1, an ABA-responsive DREB gene, plays a role in seed germination and drought tolerance of rice. Ann. Bot. 105, 401-409. doi: 10.1093/aob/mcp303

Zhao, P., Sokolov, L. N., Ye, J., Tang, C.-Y., Shi, J., Zhen, Y., et al. (2016). The LIKE SEX FOUR2 regulates root development by modulating reactive oxygen species homeostasis in Arabidopsis. Sci. Rep. 6:28683. doi: 10.1038/srep 28683

Conflict of Interest Statement: The authors declare that the research was conducted in the absence of any commercial or financial relationships that could be construed as a potential conflict of interest.

Copyright (c) 2017 Yoo, Nalini Chandran, Park, Gho, Lee, An and Jung. This is an open-access article distributed under the terms of the Creative Commons Attribution License (CC BY). The use, distribution or reproduction in other forums is permitted, provided the original author(s) or licensor are credited and that the original publication in this journal is cited, in accordance with accepted academic practice. No use, distribution or reproduction is permitted which does not comply with these terms. 